\title{
Cumulative Prospect Theory, employee exercise behaviour and stock options cost assessment
}

\author{
Hamza BAHAJI * \\ Université de Paris Dauphine, DRM Finance
}

December 2011

\begin{abstract}
This research provides an alternative framework for the valuation of standard employee stock options and for the analysis of exercise behavior patterns. It develops a binomial model where the exercise decision obeys to a policy that maximizes the expected utility to a representative employee exhibiting preferences as described by the Cumulative Prospect Theory (CPT). This model also accounts for exogenous non-market factors that may cause early exercise. Using a large database on stock options exercise transactions in 12 US public corporations, we examined the performance of our model in predicting actual exercise patterns. Interestingly, the model calibrations yield probability weighting coefficient estimates that are consistent with the estimates from the experimental literature. Further, our results suggest that the CPT-based model outperforms the Expected Utility Theory-based model in predicting actual exercise patterns in our sample. These findings convey the main contribution of this paper which is the strong ability of the CPT framework to explain the employees exercise behavior. It therefore provides rationale for using this framework in order to get more accurate fair value estimates of employee stock options contracts.
\end{abstract}

JEL Classification: G13, G30, J33, M41.

Keywords: Stock options, Exercise behavior, Cumulative Prospect Theory, Fair value, Option valuation.

\footnotetext{
* DRM- Finance, Université de Paris Dauphine, Place du Général du Lattre de Tassigny, 75 775, Paris Cedex 16, France. E-mail: hbahaji@yahoo.fr.
} 


\section{Introduction}

The extensive use of stock options in employee compensation packages and their increasing popularity as long term incentives tools have brought many of their corporate issues at the forefront of public debate. Professionals and regulators have become specifically concerned about assessing their cost to shareholders. This issue has been intensified by the requirements of accounting standards (IFRS and US GAAP) from public companies to fairly recognize the cost of stock options grants. Thus suitable expensing of employee stock options has become a focus of attention in financial accounting.

The complexity with the assessment of the stock options fair value is that their payoffs depend on the exercise behavior of the holder employee. This behavior deviates from the usual value-maximizing exercise policy stated by the standard American option theory because of many reasons. First, opposite to ordinary tradable call options, employee stock options are long-dated nontransferable ${ }^{1}$ call options. This implies that the employee has to bear the underlying risk for a long time. Second, the employee faces hedging restrictions since he is precluded from short selling the company's stock. Finally, employee holding stock options may be unable to completely diversify his stock holdings and human capital investment in the firm. Because of these features, the employee will not make the same exercise decision as an unrestricted outside investor. Therefore, the fair value of a stock option contract crucially depends on the holder employee endowment and risk preferences patterns.

Given that the values of employee stock options are unobservable, their valuation requires a theoretical modeling of the exercise policy of the holder employee. There is an extensive literature focused on this issue. Most of it relies on the Expected Utility Theory (EUT henceforth) to develop utility-maximizing binomial models (Huddart, 1994; Markus and Kulatilaka, 1994; Carpenter, 1998...). These approaches consider that the employee chooses an optimal exercise decision as part of a utility maximization problem that may simultaneously cover other issues such as consumption and portfolio choices (Detemple and Sundaresan, 1999), non-option wealth diversification or liquidity needs. Nonetheless, these models specifically rely on the validity of the underlying theoretical framework, namely the EUT.

Beyond the well known limitations of the standard normative model in explaining some patterns of economic agent behavior, it has shown handicaps in capturing some prominent features of employee equity-based compensation. For instance, EUT-based models, taking place in principalagent framework, have difficulties accommodating the existence of convex contracts as part of the

\footnotetext{
${ }^{1}$ Market experience shows however some exceptions to this feature, such like the transferable stock options programs developed by JP Morgan Chase for Microsoft in July 2003 and for Comcast in September 2004. According to this deal, JP Morgan offers the entitled employees to purchase their underwater stock options at a discount premium (i.e. below their potential market value).
} 
executive compensation package ${ }^{2}$. Consistently, studies focused on the effect of stock option and restricted stock grants on managerial effort incentives, such like Jenter (2001), Hall and Murphy (2002) and Henderson (2005), conclude that stock options are inefficient tools for creating incentives for risk-averse managers when they are granted by mean of an offset of cash compensation. This is obviously inconsistent with actual compensation practices. Moreover, a common prediction of the EUT-based models is that a risk-averse undiversified employee would value his options below their risk-neutral value (Lambert et al., 1991; Hall and Merphy; 2000, 2002; Henderson, 2005...), which contrasts to several surveys and empirical findings documenting that, frequently, employees are inclined to overestimate the value of their stock options compared to the theoretical fair market value (Lambert and Larcker, 2001; Hodge et al., 2006; Hallock and Olson, 2006; Devers et al., 2007). Furthermore, there is an empirical evidence on employees decisions, and specifically those related to the exercise of their stock options (Huddart and Lang, 1996 ; Heath et al., 1999), being driven by psychological and behavioral factors that are out of the scope of the EUT. Actually, these limitations of the EUT framework provide rationale and motivation for investigating the ability of an alternative theoretical framework to better predict employee stock option exercise patterns.

This paper develops a stock option exercise and valuation binomial model where the exercise decision obeys to a policy that maximizes the expected utility of a representative employee exhibiting preferences as described by Tversky's and Kahneman's (1992) Cumulative Prospect Theory (CPT hereafter). This model also accounts for exogenous non-market factors that may cause early exercise through an exit state that occurs with a given probability. This research aims to provide an alternative framework for the valuation of employee standard stock options contracts and the analysis of exercise behavior patterns. The purpose of this work is also to contribute to a growing literature on employee equity-based compensation that incorporates CPT-based models. These models have proved successful in explaining some observed compensation practices, and specifically the almost universal presence of stock options in the executive compensation contracts. Therefore, they have advanced CPT framework as a promising candidate for the analysis of equity-based compensation contracts. This literature includes in particular Dittmann et al. (2010) who developed a stylized principal-agent model that explains the observed mix of restricted stocks and stock options in the executive compensation packages. It also includes Spalt (2008) who used the CPT framework, and especially the probability weighting feature, to prove that stock options may be attractive to a loss-averse employee subject to probability weighting. He then explained the puzzling phenomenon that riskier firms are prompted to grant more stock options to non-executive employees. This literature comprises also Bahaji's (2011) research that elaborates on stock options incentives effect and some implications in terms of contract design aspects.

\footnotetext{
${ }^{2}$ This issue is meticulously discussed in Dittmann and Maug (2007) and in Dittmann et al. (2010).
} 
Further, I examined the performance of the CPT model in predicting actual exercise patterns in 12 US public firms over the period from 1985 to 2007. Specifically, I compared the model performance to those of two competing models, namely the EUT-based binomial model (EU model hereafter) introduced in Carpenter (1998) and the stopping-state American model (EA model in the reminder of the paper). The latter is a binomial version of Jennergren and Naslund (1993) continuous-time model. Given that some factors underlying the models are not observable, I calibrate the models on the average data from the sample using the calibration procedure in Carpenter (1998). The statistical significance tests show that the models fit the average data remarkably well. Interestingly, the base case calibration of the CPT model yielded an estimation of the probability weighting parameter that lies within the range of the experimental estimates. Next, I compared the performance of the parameterized models in predicting actual exercise patterns in the sample. I found that the CPT model brings a significant improvement over the EU model and the EA model in terms of both the size of the forecast errors and the explanatory power of the regressions. Even when relaxing the assumptions regarding the exogenous non-market factors, the CPT model yields slightly better forecasts compared to those of the EU model. Therefore, the CPT framework turns out to be the best candidate in explaining exercise patterns in the sample.

The last item discussed in this paper is the stock option fair value assessment. For the purpose of comparing the option faire value under each of the three competing models, I assessed the fair value of the stock option contract for the representative firm in the sample (i.e. the average firm). In addition, for the purpose of comparison with some methods recommended by the international accounting standards and largely indoctrinated by practitioners, I computed option fair values using two benchmark models. The first one is the extension of the Black \& Scholes model (BS henceforth) that uses the expected lifetime of the option as an input instead of its contractual expiration date. The second benchmark is the Hull and White (2004) model. The results show that, on the one hand, the CPT model and the EU model yielded values are close (a difference of about $4 \%$ ) and that, on the other hand, the values from the three models are significantly lower than the values computed based on the two benchmark approaches. Specifically, if we consider that the CPT model is the most accurate model in the sense that it predicts the best exercise patterns, we would admit that the benchmark models overestimate the value of the representative company's stock option contract by $10 \%$ to $20 \%$. Another finding from this analysis is that the models display different sensitivities to market factors, especially volatility and dividend yield. These sensitivities depend also on the models specifications.

The remainder of the paper is structured as follows. In the $1^{\text {st }}$ section stock option exercise and valuation related literature is reviewed. The $2^{\text {nd }}$ section sketches a theoretical framework for stock option exercise from the perspective of a CPT representative employee and describes, step-by-step, the construction of the CPT model and the implied exercise prediction statistics. This section also 
provides some numerical analyses of the model sensitivity to the preferences-related factors. Section 3 presents the empirical analysis comparing the predictive power of the models regarding actual exercise patterns in a sample of 12 US firms in the NYSE and the NASDAQ. The last section discusses the stock option fair value estimates from the models.

\section{Stock option exercise and valuation: related literature}

With the increasing interrogations surrounding the use of employee stock option, their exercise and valuation issues have become a focus of interest of a rapidly growing literature. This literature includes several empirical studies that attempted to bring the spotlight on the determinants of early exercise patterns. Hemmer et al. (1996), Core and Guay (2001) and Bettis et al. (2005) investigated economic/rational factors driving exercise decisions such as liquidity needs and risk diversification. Huddart and Lang (1996) studied the exercise behavior of over 50,000 employees at eight corporations. They mainly found that exercise is strongly associated with recent stock price movements. Heath et al. (1999) have found empirical evidence suggesting that psychological factors may also lead the employee to sacrifice some option value by exercising it early. Consistently, Bahaji (2009) showed that stock option exercise patterns in 12 US companies display myopic behavior denoting the well documented mental accounting behavioral bias. Sautner and Weber (2005) also provided some interesting empirical results suggesting that employees exercise decisions denote psychological bias, such as miscalibration and mental accounting. This line of studies also includes Core and Guay (2001), Misra and Shi (2005) and Armstrong et al. (2006). All these studies provide rationale for behavioral factors to be considered in a theoretical framework for employees exercise decisions.

One approach that has been suggested in the literature to address the problem of nontransferability and hedging restrictions effects on exercise behavior is to model the employee exercise policy relying on the EUT framework. These papers characterized the optimal exercise policy by a utility-maximization problem. Huddart (1994) and Kulatilaka and Marcus (1994) were the first to have introduced binomial models where the exercise occurs as soon as the utility from the exercise proceeds exceeds the expected utility from holding the option for another period, with non-option wealth invested in the risk-free asset. Carpenter (1998) extended this approach to take into account early exercise or forfeiture due to job termination, using an exogenous Poisson process with a given stopping rate ${ }^{3}$. Another improvement brought by Carpenter (1998) is the investment of the employee non-option wealth in the Merton optimal portfolio instead of the risk-free asset. She calibrated her model to mean exercise data from a sample of 40 US firms. She found that, surprisingly, the EU model performs almost as good as a simple extension of the usual binomial model including an

\footnotetext{
${ }^{3}$ Papers that focused on the impact on the stock option fair value of forfeiture and early exercise due to job termination include Jennergren and Naslund (1993), Cuny and Jorion (1995) and Rubinstein (1995).
} 
exogenous stopping state, which suggests that "exercise patterns can be approximately replicated merely by imposing a suitable stopping rate, without the need to make assumptions about [...] risk aversion, diversification, and the value of new employment ". Detemple and Sundaresan (1999) suggested an extension that allows for simultaneous portfolio choice and stock option exercise decisions. Bettis et al. (2005) built on Carpenter's (1998) approach to carry out an analysis of exercise patterns within a sample of 140,000 option exercises by corporate executives at almost 4,000 firms. They calibrated the EU model to their median data. Their results contrast with those of Carpenter (1998) in that they show that the EU model outperforms the stopping state binomial model in forecasting exercise behavior.

Another line of studies has advocated an approach based on exogenous specification of the exercise policy. Rubinstein (1994) and Cuny and Jorion (1995) built stock option pricing models under exogenous assumptions about the exercise timing. Jennergren and Naslund (1993) and Carr and Linetsky (2000) derived analytical valuation formulas assuming exogenous specified forfeiture rates and exercise boundaries. Moreover, a paper by Hull and White (2004) proposed a binomial model assuming that vested options are exercised whenever the stock price hits an exogenous hurdle specified as a multiple of the stock price at inception. Their approach also allows for the possibility that the option holder might have to leave the firm for exogenous reasons and, therefore, needs to forfeit or exercise his options provided these are in-the-money. Relying on Hull's and White's approach, Cvitanic et al. (2004) provided an analytical pricing formula. However, Carpenter et al. (2010) showed that the optimal exercise policy needs not to be specified in the form of a single critical stock price boundary. They nevertheless proved under the risk-neutral probability measure the existence of a single stock price exercise boundary for CRRA utility functions with risk aversion coefficient less than or equal to one.

More recent literature has underscored the relevance of valuation approaches that proceed by using empirically estimated exercise hazard functions to describe the stock option's expected payoff. Carpenter et al.(2006) suggested a method - similar to that used for the modeling of the prepayment of the mortgage-backed securities - relying on estimated exercise and cancellation rates as a hazard function of the stock price path, time to expiration and both firm and option holder characteristics. Armstrong et al.(2006) modeled exercise rates as a function of idiosyncratic behavioral and economic factors such as attainment of performance benchmarks, recent vesting, portfolio value, and employee rank. They proved that estimates from an idiosyncratic exercise rate model are also more accurate in predicting out-of-sample realized option values.

Finally, several researches have attempted to undertake the issues related to reloading and resetting features' effect on stock options exercises and valuation (Hemmer et al., 1998; Saly et al., 
1999; Dybvig and Loewenstein, 2003...), whilst other studies have focused on valuation issues related to block exercise behavior (Henderson, 2006; Grasselli and Henderson, 2009).

\section{The CPT exercise model}

This section develops a model of stock options exercise and valuation from the viewpoint of the issuer (i.e. the firm). The model is based on a theoretical framework where the option cash flows depend on the exercise behavior of a representative option holder whose risk preferences fit with the CPT framework. This section provides in addition some numerical analyses of the sensitivity of the model outputs to risk preferences parameters.

\subsection{The economy of the stock option contract}

The representative employee is assumed to be granted a stock option contract at time $t=0$ expiring within a time period " $T$ ". The contract is a Bermudan style call option on the common stock of the company denoted by " $S_{t}$ ”, with strike price " $K$ ”. It includes two restrictions as commonly do standard employee stock options. The first one is the non-transferability, which means that the employee is precluded from selling the option. The second one is the vesting, which implies the Bermudan feature of the option. The vesting restriction requires the cancellation of the contract in case the holder leaves the company before the end of the vesting period " $t_{v}$ ". In addition, I assumed that the employee is not allowed to short-sell the company stock and that he can earn the risk-free rate " $r$ " from investing in a riskless asset. Hence, this assumption stands for a restriction on the hedging of the option.

Moreover, the underlying is assumed to follow a standard CRR binomial process with " $N$ " time steps. Thus, in each time step " $\delta t=T / N$ " the stock price may move up by a factor " $u=e^{\sigma \sqrt{\delta t}}$ " with a probability " $p=\frac{e^{(\mu-q) \cdot \delta t}-u}{u-1 / u}$ " or down by factor " $d=1 / u$ ". " $\sigma$ ", " $\mu$ " and " $q$ " are the stock price volatility, the expected return and the dividend yield respectively. Note that the upward risk neutral probability is given by: $p^{*}=\frac{e^{(r-q) \cdot \delta t}-u}{u-1 / u}$.

Furthermore, following Carpenter (1998), I assumed that in each time period there is an exogenous probability " $p_{e}$ " for the employee to be offered a cash amount " $y$ " per each option held to leave the company. Leaving the company implies that the option contract is stopped at that time either through exercise, provided the option is vested and is in-the-money, or forfeiture if not.

\subsection{Risk preferences of the representative employee}


I assumed that the representative employee exhibits preferences as described by the CPT (Tversky and Kahneman, 1992). It follows that to each gamble " $x$ " with countable outcomes " $x_{i \in\{1, \ldots, n\}}$ " and their respective probabilities " $p_{i \in\{1, \ldots, n\}}$ ", the employee assigns the value:

$$
V(x)=\sum_{i=1}^{n} \omega_{a, i} v_{\theta}\left(x_{i}\right)
$$

Where the function $v_{\theta}($.$) , called the value function, is assumed of the form:$

$$
v_{\theta}(y)=\left\{\begin{array}{c}
(y-\theta)^{\alpha} ; y \geq \theta \\
-\lambda(\theta-y)^{\alpha} ; y<\theta
\end{array}, \text { where } 0<\alpha \leq 1 \text { and } \lambda \geq 1\right.
$$

This formulation has some important features that distinguish it from the normative utility specification. The value function is defined on deviations from a reference point, denoted by " $\theta$ ". It is concave for gains (i.e. implying risk aversion) and commonly convex for losses (i.e. implying risk seeking) due to parameter " $\alpha$ ". It is steeper for losses than for gains (i.e. conveying a loss aversion feature caught up through " $\lambda$ ”).

The terms " $\omega_{a, i}$ " in (1) are decisions weights associated to each outcome. These result from a transformation of the probabilities using a weighting function " $\psi_{a}($.$) ". It applies to cumulative$ probabilities, represented by the cumulative probability function " $F($.$) ", as follows:$

$$
\omega_{a, i}=\left\{\begin{array}{lr}
\psi_{a}\left(\sum_{j=i}^{n} p_{j}\right)-\psi_{a}\left(\sum_{j=i+1}^{n} p_{j}\right)=\psi_{a}\left(1-F\left(x_{i-1}\right)\right)-\psi_{a}\left(1-F\left(x_{i}\right)\right) & ; x_{i} \geq \theta \\
\psi_{a}\left(\sum_{j=1}^{i} p_{j}\right)-\psi_{a}\left(\sum_{j=1}^{i-1} p_{j}\right)=\psi_{a}\left(F\left(x_{i}\right)\right)-\psi_{a}\left(F\left(x_{i-1}\right)\right) & ; x_{i}<\theta \\
\psi_{a}\left(p_{i}\right) & ; i=\{1, n\}
\end{array}\right.
$$

Following Tversky and Kahneman (1992), the probability weighting function is assumed of the form:

$$
\psi_{a}(p)=\frac{p^{a}}{\left(p^{a}+(1-p)^{a}\right)^{\frac{1}{a}}} \text { where } 0.279<a \leq 1
$$


This function stands for another piece of the CPT, which is the nonlinear transformation of probabilities. Specifically, it captures experimental evidence on people overweighting small probabilities and being more sensitive to probability spreads at higher probability levels. The degree of probability weighting is controlled separately over gains and losses by the weighting parameter " $a$ ". The more this parameter approaches the lower boundary ${ }^{5}$ at 0.279 the more the tails of probability distribution are overweighted. For instance, when we set " $a$ " to 1 , probability weighting assumption is relaxed.

\subsection{Setting up the CPT model}

Using an alternative behavioral framework, the CPT model builds on prior works by Huddart (1994), Kulatilaka and Marcus (1994) and Carpenter (1998) in that it uses the same principle governing the exercise decision. Similar to these models, the CPT model is a two-state lattice where the optimal exercise decision is driven by the maximization of the expected utility from exercise proceeds. According to this maximization principle, the option is exercised in a given time period if the utility from the exercise proceeds at that time is higher than the expected utility from continuing to hold the option until the next time period. With that said, the representative employee is supposed to exercise as soon as the intrinsic value of the option exceeds the value of the option from his own perspective (i.e. the subjective value). However, opposite to these models, the utility is assessed using the CPT framework instead of the EUT. Therefore, the key differentiating point is that, on the one hand, only the utility of exercise proceeds is considered rather than that of total wealth and, on the other hand, the expected utility is assessed based on weighted reel probabilities.

\subsubsection{Model construction}

The first step of the CPT model construction consists in determining the weighted transition probabilities that will be used to assess the utility expectation at each node of the share price binomial tree. The purpose is to build in parallel to the share price binomial process a distorted/skewed twostate process that fits with the employee view of probabilities as specified by the CPT probability weighting function ${ }^{6}$ in (4). This process relies on a probability tree with the same share price nodes as

\footnotetext{
${ }^{4}$ Actually, according to the CPT, the degree of probability weighting is controlled separately over gains and losses through two different weighting parameters, " $a$ " and " $b$ " respectively. For simplicity, I assumed these parameters to be equal (i.e. $a=b$ ).

${ }^{5}$ The lower boundary at 0.279 is a technical condition to insure that “ $\frac{\partial \psi_{a}(p)}{\partial p}$ " is positive over ]0,1[ as required by the following first order condition: $(a-1) p^{a}+(a(1-p)+p)(1-p)^{a} \geq 0$. This constraint insures that the probability weighting function can not assign negative decision weights consistent with first order stochastic dominance. For farther details see Ingersoll (2008).

${ }^{6}$ An interesting alternative to the CPT probability weighting function is to use weighting functions implied by listed options prices. This approach uses non-parametric methods to estimate state price densities from options
} 
the binomial tree. The approach used to build this tree is described through the set of equations in appendix A1. As stated, this approach keeps the original share price nodes unchanged and uses forward induction to recover all transition probabilities starting from the root of the tree.

The second step in building the model is about setting the patterns of exercise decision. Following Carpenter (1998), I accommodate the possibility of option forfeitures or early exercises caused by non-market events, such as liquidity shocks, employment termination or any other forced exercise through the exit states. Note that the exit decision is an endogenous feature of the model in that it is linked to the size of the cash amount " $y$ " offered to the employee to leave. In addition, I assumed that the exercise decision in a given time period depends on whether or not the exit state is prevailing at that time, the vesting status of the option and the prevailing level of stock price, but not the past stock price path. This assumption allows for backward recursion approach.

Moreover, as stated in assumption 1 bellow, the employee is supposed to set his reference point based on his initial own share price return expectations over the lifetime of the option:

Assumption 1: the reference point " $\theta_{i}$ " at a time period " $t_{i}$ " is defined as the intrinsic value resulting from a time-adjusted growth rate of the share price based on the annualized return " $\rho$ " reflecting the expectations of the employee:

$$
\theta_{i}=\left(S e^{(\rho-q) i \delta t}-K\right)^{+}
$$

While this setting is inconsistent with empirical evidence on employee exercise activity being linked to share price historical maxima (Huddart and Lang, 1996; Heath et al, 1999; Bahaji, 2009), it nevertheless conveys an exercise behavior taking into account non-status quo reference points. Actually, under a path-dependent specification of the reference point, backward recursion becomes impossible in our situation. The specification in (5) is also supported by Hodge et al. (2006) findings that employees usually use heuristics to attach values to their stock options, like determining the intrinsic value from their expectations about future stock price. Recall that although the CPT specifies the shape of the value function around the reference point, it does not provide guidance on how people set their reference points. Neither does most of the psychological literature relying on the assumption according to which the reference point is the Status quo. Instead, this literature admits both the existence and the importance of non-status quo reference points since "there are situations in which gains and losses are coded relative to an expectation or aspiration level that differs from the status

market prices. These estimates are then used as building blocks to construct non-parametric estimators of the weighting function without imposing any constraint on the shape of the former. For more details on this approach see Polkovnichenko and Zhao (2009). 
quo" (Kahneman and Tversky, 1979). Research on the Disposition Effect ${ }^{7}$ has paid greater attention to this issue (Shefrin and Statman, 1985; Heisler, 1998; Odean, 1998a). These studies have found strong evidence on reference points being set in a dynamic fashion. Moreover, literature on reference point adaptation is still developing. This literature includes few papers such as Koszegi and Rabin (2006) and Yogo (2005) that posit that people set their reference point based on their expectations about the future instead of the starting point (ex: original purchase price). It also includes researches that provided experimental evidence on people using historical maxima as reference points (Gneezy, 1998), shifting their reference points after a stimulus is presented (Chen and Rao, 2002) and adapting them asymmetrically more completely over gains than over losses (Arkes et al.; 2006).

Finally, I made the following assumption regarding block exercise (i.e. policy of spreading exercise over several separate transactions) that implies that the exercise in the CPT model is an "all or nothing" exercise policy:

Assumption 2: when the employee decides to exercise, he will do so for all his outstanding options at once in a single block provided these options are part of the same grant and, therefore, have the same characteristics.

\section{Figure-1: Illustration of the CPT model construction.}

This figure exhibits the structure of the CPT model tree at node $(i, j)$. The upper branches represent the exit state. Equation (5.1) formulates the exercise outcome related to that state. Equation (5.2) gives the exercise outcome at the continuing state represented by the lower branches. Equations (5.3) and (5.4) provide, respectively, the option risk neutral value and subjective value.

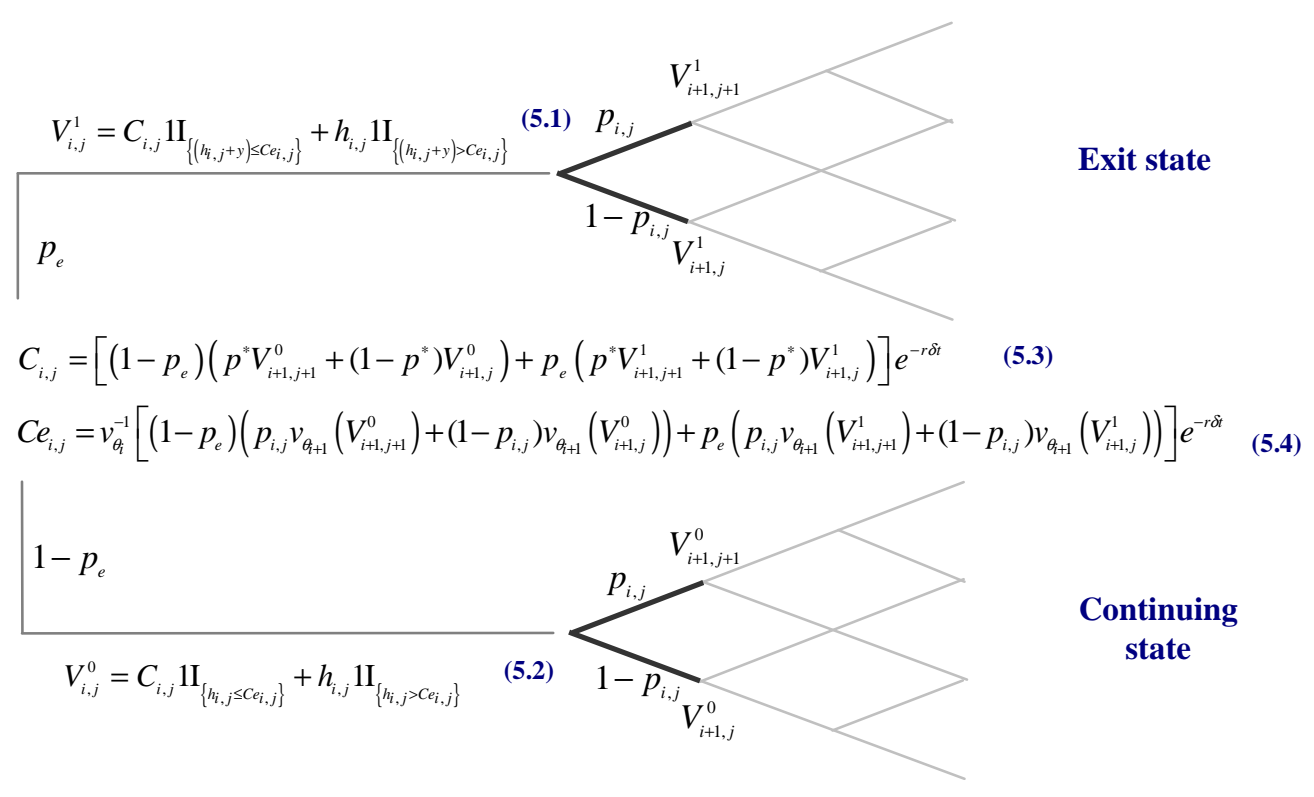

Notation

- $h_{i, j}$ : Intrinsic value of the option at note $(i, j)$.

- $p_{i, j}$ : Weighted transition probability at node $(i, j)$.

- $p^{*}$ : Risk neutral transition probability at node $(i, j)$.

- $C e_{i, j}$ : Subjective value of the option at node $(i, j)$ determined based on the certainty equivalence principle.

- $C_{i, j}$ : Risk-neutral value of the option at node $(i, j)$.

- $V_{i, j}^{0}$ : Continuing state exercise decision outcome at node $(i, j)$.

- $V_{i, j}^{1}$ : Exit state exercise decision outcome at node $(i, j)$.

- $\theta_{i}$ : Reference point at the $i^{t^{t h}}$ level of the tree.

\footnotetext{
${ }^{7}$ Disposition effect is a term coined by Shefrin and Statman (1985) to refer to the tendency of individual investors to hold loser stocks and sell winner stocks defined relative to a purchase price reference point.
} 
Figure-1 exhibits the construction of the model at the $j^{\text {th }}$ node of the $i^{\text {th }}$ level of the tree (i.e. at time " $t_{i}=i . \delta t$ ") denoted by $(i, j)$. The option is assumed to have already vested at that level. As illustrated, the exercise decision relies on the subjective value of the option considering four states of the world (i.e. stopping/continuing states combined with upward/downward sates). The latter is assessed over these four states based on the certainty equivalence principle using the weighted transition probabilities and the exit probability. Thus, in the continuing state, the option is exercised as soon as the intrinsic value exceeds the subjective value of the option. However, in the exit state, the employee decides to continue with the option if its subjective value is greater than the sum of its intrinsic value and the cash amount he is offered to leave the company. By repeating this process using backward recursion, starting from the end of the tree, we can find out the nodes where the option is exercised. Note that at the levels where the option is still unvested, it is systematically held to the next period provided the employee is in the continuing state. Nevertheless, unvested option is forfeited in the exit state if its subjective value is lower than the leaving-cash amount. A formal algorithm describing the discussed exercise rule is provided in the appendix A2.

\subsubsection{Model outputs and predictions}

Similar to Carpenter (1998) and others, I considered that the employee exercise patterns are characterized by two main variables: the exercise stock price ratio, defined as the stock price-to-strike price ratio at the time of exercise, and the lifetime of the option, denoted respectively by " $S_{\tau}$ " and " $\tau$ ". It follows that the statistics of interest denoting the exercise patterns predictions implied by the model are the expectations of these two random variables subject to the final share price:

$$
\begin{aligned}
& \hat{S}_{\tau}=I E^{p}\left(S_{\tau} \mid s_{T}^{*}\right) \\
& \hat{\tau}=I E^{p}\left(\tau \mid s_{T}^{*}\right)
\end{aligned}
$$

Where " $I E^{p}(. \mid$.$) " is the conditional expectation operator under the reel probability measure.$

Specifically, the expectations above are determined as the weighted average of the outcomes of the random variables " $S_{\tau}$ " and " $\tau$ " across all the stock price paths that result in an exercise and settle at a final stock price level " $s_{T}^{*}$ ". Note that these predictions take into account the effect of the share price effective performance on the exercise behavior since they are conditioned on the terminal share price level. This makes them comparable to equivalent mean values from empirical data, which enables to test the model prediction power and to calibrate it (i.e. estimate the unobservable parameters of the model). 
The expected value of the cancellation rate " $\eta "$ is another model-yielded variable that has to be considered for the purpose of calibration on empirical data:

$$
\hat{\eta}=I E^{p}(\eta)
$$

The estimation of this statistic consists in recursively computing the 1-year cancellation probability based on the implied distribution of the cancellation state variable across all share price paths. Therefore, it may be interpreted as the average ratio of cancelled options during a year either through forfeitures or expirations. Note that, opposite to the two previous statistics in (6) and (7), the mean cancellation rate is not conditioned on a final share price level. Let's stress also that the cancellation rate has to be distinguished from the exit rate. The latter is the model input that drives the frequency of forfeitures prior to the expiry date, whereas the former is a model output that results from the implied exercise policy and, consequently, depends on the model parameters and especially the exit rate.

\subsubsection{Model drawbacks}

The CPT model assumes that when the employee decides to exercise he will do it for all his options at once. It therefore ignores the possibility of fractional exercise ${ }^{8}$ (i.e. the tendency of employees to exercise large quantities of options on a small number of occasions) in spite of its empirical evidence (Bahaji, 2009). In addition, the model do not account for tax constraints effect on exercise decision. Moreover, the influence of private information that may be held by the employee, as an insider, on his exercise behavior is left out as well. The model ignores also the potential dependence of the exercise policy of the employee on the compensation policy of the firm and vice versa. Finally, let's emphasize that the model predictions are contingent to the validity of the underlying theoretical frame work (i.e. the CPT). In fact, since stock options subjective values are not observable, the obvious recourse is to rely on a theoretical framework in order to specify the exercise policy of a representative employee. If at least subjective values were observable for European call options, one could use them as building blocks to construct an implied share price lattice ${ }^{9}$. Actually, we can demonstrate in a continuous time setting, under some technical assumptions, the existence of a stock price diffusion process that is compatible with these subjective values (see appendix A3). This implied stock price diffusion allows reproducing all input subjective values and, therefore, integrates employee risk preferences patterns. Once discretized, using for instance lattice approaches, it could be used as an alternative for the valuation of standard employee stock options (i.e. Bermudan-style stock options).

\footnotetext{
${ }^{8}$ Many authors have suggested models that take into account individual exercise as well as block exercise behavior: see for example Henderson (2006) and Carpenter et al.(2006).

${ }^{9}$ See for instance Derman and Kani (1994), Rubinstein (1994) and Derman et al.(1996).
} 


\subsection{Some numerical simulations}

In order to provide a concrete outline on the profile of the outputs yielded by the model along with their respective sensitivities to some parameters of the model, in particular those specific to the CPT (i.e. preferences-related parameters), I performed numerical analyses based on a base case setting of the stock option contract conditions and the preferences parameters of the representative employee.

\subsubsection{A numerical application}

Consider the case of a representative employee who holds a 4-year at-the-money (ATM henceforth) stock option ( $T=4)$ vesting in a year $\left(t_{v}=1\right)$ with a strike price " $K=1$ ". For the remaining option-related parameters, assume no dividend payments $(q=0)$, a stock price volatility at " $\sigma=30 \%$ ", a risk-free rate " $r=3 \%$ " and an expected stock price return of " $\mu=7 \%$ ". In addition, let's set the curvature parameter of the value function " $\alpha$ ", the probability weighting factor " $a$ " and the loss aversion coefficient " $\lambda$ " at respectively $0.88,0.64$ and 2.25 based on the experimental estimates from the CPT (Tversky and Kahneman, 1992). Moreover, to calibrate the reference point function in (5), we will set the parameter " $\rho$ " at $10 \%$, which boils down to assuming that the representative employee assesses his gains and losses over the option holding period with respect to a share performance hurdle of $10 \%$ per annum. Finally, we will consider that, each year, the representative employee is offered an amount " $y=0.30$ " to leave the company with a probability " $p_{e}=0.25$ ".

Panel-2 of figure-2 exhibits the standard CRR binomial stock price tree resulting from the setting above. The share price upward and downward movers are generated by factors " $e^{+\sigma \sqrt{\delta t}} \approx 1.35$ " and “ $e^{-\sigma \sqrt{\delta t}} \approx 0.74$ " respectively using yearly time step " $\delta t=1$ ". The risk-neutral transition probability at every node is " $p^{*} \approx 0.475 "$. The yearly reel transition probability is " $p \approx 0.545 "$. It implies the weighted transition probability tree displayed in Panel-1. As we can see, the weighted transition probability is increasing with the share price and tends to be higher than the reel transition probability at the upper nodes. This result conveys the well established phenomenon on individuals overweighting small probabilities. Given the profile of the weighted transition probabilities, the representative employee is expected to value his option in excess of its risk-neutral value at upper nodes. Therefore, he will delay exercise at these nodes. Actually, we can see this when looking at Panel-3 and Panel-4: the subjective values are higher than the risk neutral values at the upper nodes. To get a more concrete outlook on that, let's focus on nodes A, B and C. The intrinsic value of the option at node A is " $h_{3,3} \approx 1.460 "$ while the subjective value is " $C e_{3,3} \approx 1.855 "$ ". At the continuing state, the employee will delay then the exercise since the option is worth, from his own perspective, much more than its intrinsic value. He will not exercise under the exit state neither because the exit amount is not 
sufficient to make exercise attractive to him $\left(h_{3,3}+y \approx 1.760<C e_{3,3}\right)$. According to the adjacent nodes at the higher level (i.e. in year 4 ), the option risk-neutral value at node $\mathrm{A}$ is " $C_{3,3} \approx 1.489$ ". In contrast, the employee will exercise the option at node B, provided he is at the continuing state, since he would undervalue it relative to its intrinsic value: " $h_{3,2} \approx 0.350$ " in versus of " $C e_{3,2} \approx 0.332$ ". This means that he should exercise the option at the exit state either. Exercise decisions at nodes A and B yield the risk-neutral value of the option at node C: " $C_{2,2}=p^{*} h_{3,2}+\left(1-p^{*}\right) C_{3,3} \approx 0.865$ ”. Similar to node A, the employee will not exercise at that node under both states. This process is reiterated using backward recursion to get the option risk-neutral value at inception (i.e. at time $t=0$ ), which turns out to be lower than the subjective value: " $C_{0,0} \approx 0.236$ " in versus of " $C e_{0,0} \approx 0.271$ ". It follows that the employee is much more interested in receiving stock options than a risk-neutral agent would be. Assuming the company and the employee bargain efficiently over the terms of compensation, the company will grant him more options by mean of an offset of other compensation components (Bahaji, 2011). Finally, note that the expected lifetime of the option conditioned on a terminal share price level of " $s_{4}^{*}=2$ " is about 2.88 . The conditional expected exercise ratio is almost 1.45 and the expected annual cancellation rate is $12.88 \%$.

Figure-2: A numerical example on the CPT model implementation.

This figure exhibits an example on the numerical implementation of the CPT model based on an annual time step setting. Figures were computed

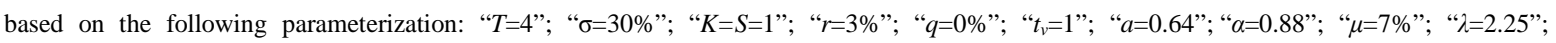
" $q_{e}=0.25$ "; " $y=0.30 " ; " \rho=10 \% "$. Panel-1 shows the weighted transition probabilities computed based on the approach described in appendix A1. Panel-2 exhibits the share price binomial tree. Panel-3 and Panel-4 show, respectively, the option subjective values and risk-neutral values computed using the algorithm in appendix A2. In each panel, nodes show the value of the variable of interest.
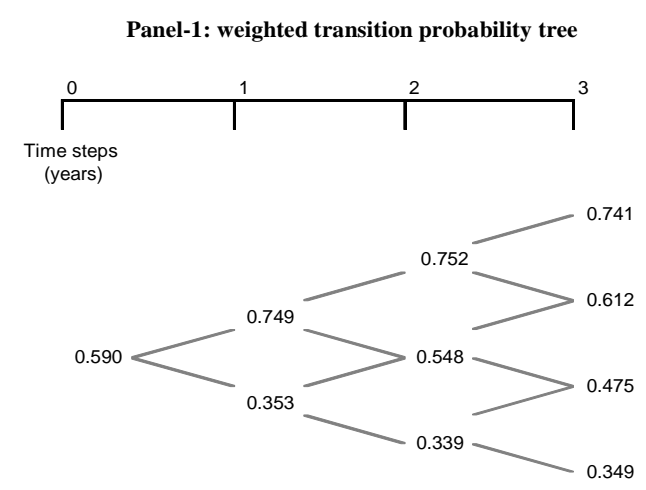

Panel-3: option subjective values

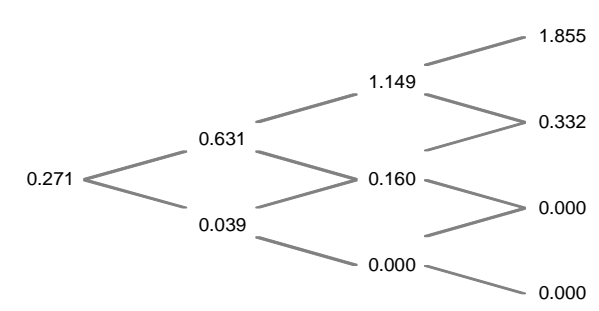

Panel-2: share price tree

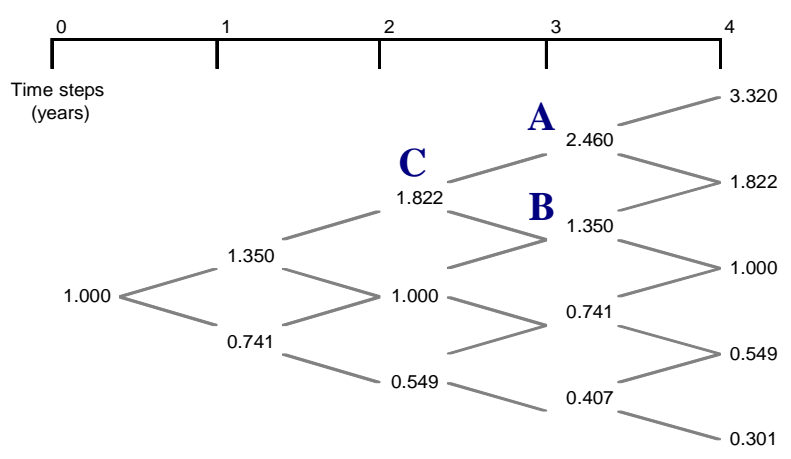

Panel-4: option risk-neutral values

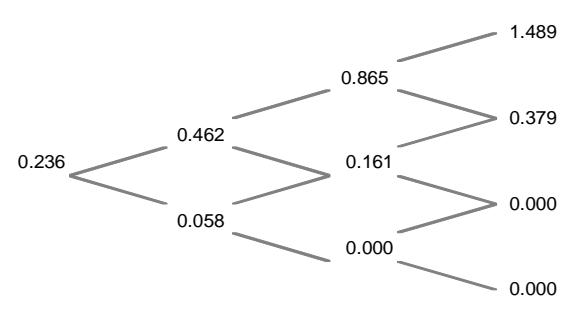




\subsubsection{Sensitivity analysis with respect to preferences parameters}

To analyze the sensitivity of the model outputs to some parameters, mainly those defining the employee preferences, I used the same base case parameterization. In order to gain in accuracy, the model is switched to a monthly time step setting ( $\delta t \approx 0.083$ ). The analysis consists in computing the model outputs within a range of values of the parameters we are interested in.

Graph-1 depicts the model outputs as functions of the reference point parameter " $\rho$ ". At first sight, the fair value of the option (i.e. the risk-neutral value) is decreasing in this parameter (see the blue solid curve). This result suggests that the higher the employee sets his reference point, the earlier he will exercise his option, which is consistent with the profile of the conditional expected lifetime function represented by the red dashed curve. Graph-3 shows similar patterns regarding loss aversion $(\lambda)$ : the conditional expected lifetime, the conditional expected exercise ratio and, consequently, the fair value of the option are decreasing with respect to loss aversion. Graph-6 also exhibits comparable patterns with regards to the value function curvature parameter " $\alpha$ ": the more curved the value function the earlier the exercise decision. On the other hand, graph-2 exhibits opposite behavior of the output functions relative to the probability weighting degree " $a$ ". The red dashed curve, the gray dashed curve and the blue solid curve show respectively that the conditional expected lifetime, the conditional expected exercise ratio and the fair value of the option are increasing in the degree of probability weighting (resp. decreasing in " $a$ "). Actually, the impact of the parameter driving the employee risk-preferences is embedded in the subjective value. It is mechanically transmitted through this vehicle to the employee exercise decision and, therefore, to the fair value of the stock option. To leave nothing in doubt, one can easily demonstrate that subjective value is decreasing in loss aversion and reference point and increasing in the degree of probability weighting ${ }^{10}$.

In addition, I performed a similar analysis in order to show the behavior of the model with respect to the parameters standing for the non-market factors, namely the exist probability " $p_{e}$ " and the leaving amount " $y$ ". The results are plotted in graph-4 and graph-5. As expected and stated earlier in this paper, the charts show that the option fair value is a decreasing function of the exit probability and the leaving amount (see the blue solid curves). This means that the more the employee is prompted to leave the company, the earlier will he exercise the option. Consistently, the red dashed curves show that the expected cancellation rate is increasing with these parameters of interest.

\footnotetext{
${ }^{10}$ For farther details see Bahaji (2011)
} 
Figure-3: Numerical sensitivity analyses.

This figure exhibits the results of the model outputs sensitivity analyses with respect to the preferences-related parameters and parameters driving non-market factors. The analyses are based on a monthly time-step setting and use numerical approach. Figures were computed based

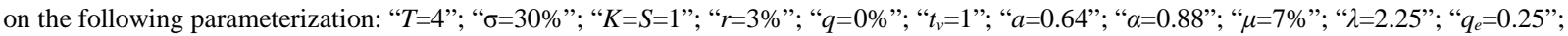
" $y=0.30$ "; " $S_{T}^{*}=1$ "; " $\rho=10 \%$ ". Graph-1, Graph-2, Graph-3 and Graph-6 show the model outputs as functions of, respectively, the reference point, the probability weighting, the loss aversion and the curvature parameters. Graph-4 and Graph-5 plot the stock option fair value and the expected cancellation rate against, respectively, the severance (or leaving) amount and the exit probability.
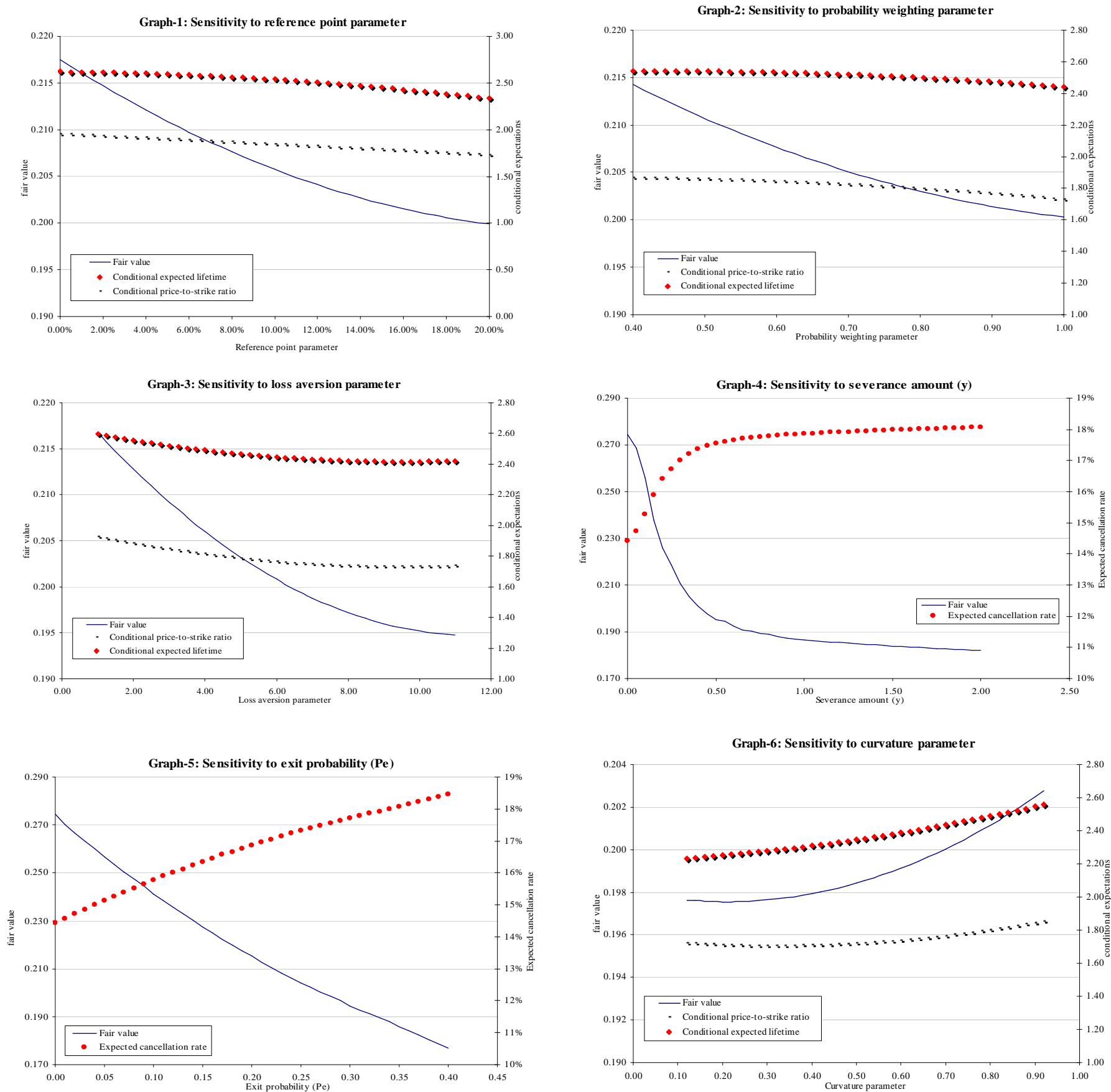


\section{The empirical analysis}

In this section, I examine the performance of the CPT model in predicting actual exercise patterns in 12 US firms over the period from 1985 to 2007. Specifically, I compare the model performance to those of two competing models, namely the EU model and the EA model.

The EU model used is similar to that introduced by Carpenter (1998) and empirically tested latter by Bettis et $a l$. (2005) ${ }^{11}$. As in Huddart (1994) and Marcus and Kulatilaka (1994), this model is based on a binomial stock price tree where the exercise decision is made according to a policy that maximizes the expected utility subject to hedging restrictions. The option holder utility function is assumed to be of the isoelastic form: " $u(w)=w^{1-\gamma} /(1-\gamma)$ " where " $\gamma$ " is the constant relative risk aversion coefficient. " $w$ " is the employee outside wealth (i.e. non-option holding wealth) normalized by the value of the stocks underlying the granted stock options. Moreover, similar to the CPT model, in each time step there is an exogenous probability " $p$ " that the employee is offered a cash amount " $y$ " to leave the firm. This allows accommodating the possibility of option forfeiture or an early exercise due to non-market events. In addition, the outside wealth as well as any early exercise proceeds are assumed to be invested in the constant proportion portfolio of the company's stock and a risk-free bond that would be optimal for the employee to hold in the absence of the stock option and the possibility of receiving " $y$ ". This optimal portfolio is a binomial version of the continuous-time portfolio developed by Merton $(1969,1971)$. For further details regarding the EU model algorithm the reader is referred to Carpenter (1998).

The EA model is a binomial variant of the continuous-time model of Jennergren and Naslund (1993). The only difference between this model and the standard American option model is the stopping event that occurs with some exogenous probability " $p$ ”. This exit state captures all the factors that might cause a deviation from the standard theory exercise policy such as employment termination, liquidity needs or a desire for diversification. The algorithm of this model is also elaborately described in Carpenter (1998).

The CPT model is expected to outperform the two competing models because of two reasons. First, the CPT, thanks specifically to the key feature of probability weighting, has proven fertile in explaining stock option subjective valuation patterns (Spalt, 2008; Bahaji, 2011), which makes it a promising candidate for analyzing the employee exercise behavior. Secondly, there exists empirical and experimental evidence on behavioral factors affecting employees exercise policies. Contrary to the normative framework, the CPT is expected to accurately capture these factors since it is a descriptive theory of the way people formulate their risky preferences.

\footnotetext{
${ }^{11}$ The version used in this research ignores the leaving amount " $y "$.
} 
The remainder of this section is organized as follows. Subsection 4.1 provides a description of the data and the construction of the variables used for this analysis. Subsection 4.2 presents the models calibrations and the methodology used to assess the performance of each model in predicting exercise patterns in the sample. Subsection 4.3 discusses the results and draws some preliminary conclusions. The last subsection provides additional robustness analyses.

\subsection{Data set and construction of the variables}

\subsubsection{The data sample}

The data used in this research is a private data provided by a top-tier US actuary company. It includes extensive information on stock options exercises and cancellations for 12 US firms in the NYSE and the NASDAQ (6 of them are large caps). One of these firms was acquired in 2006, and consequently unlisted since then (see company F7 in table-1). As reported in table-1, the data set is about 542 stock options plans granted over the period from 1983 to 2006 to 7,125 employees ${ }^{12}$ located in 16 different countries. However, it is important to underline that $98 \%$ of the stock options holders are based in the USA. The plans expiration periods range from 5 to 10.5 years.

More specifically, the database includes details on individual grants characteristics, namely the employee ID, the plan ID, the number of granted options, the option strike price, the vesting schedule and the expiry date. It also comprises the following items regarding 35,086 individual exercise transactions related to these grants: the employee ID, the plan ID, the exercise date, the exercise stock price and the number of exercised options. In addition, the database contains employee-by-employee information on granted options forfeitures, mainly including the forfeitures dates, the number of options forfeited and the related plan ID. In order to cover all the events of zero-payouts and cancellations, I identified all the plans that expired worthless (i.e. resulting in zero payout at maturity) using share price data from Bloomberg proprietary database. I then determined for each employee the number of outstanding options that ended in a zero payoff by crossing their granted plans IDs with the IDs of the plans identified in the previous step. I obtained a total number of 49,210 individual cancellation/expiry cases. The breakdown of this figure with respect to each firm is reported in table-1.

Recall that the focus of this research is the exercise patterns of standard employee stock options. Therefore, I dismissed from the dataset all the items related to specific grants with a vesting subject to performance conditions. Actually, the initial dataset included 1,251 exercise transactions related to 7 performance stock option plans. All these specific plans were granted to top executives and senior managers. The 542 plans comprised in the scope of this study are Bermudian-style stock option contracts with a vesting schedule subject to service conditions. Some contracts are immediately vested (i.e. do not include vesting periods). The other contracts include either a cliff vesting or a gradual

\footnotetext{
12 The term "employee" is used to refer to all company insider labour categories, including executives as well as non executive employees.
} 
vesting. Vesting periods range from 2 to 9.5 years. All the contracts were granted almost at-the-money and do not comprise buyback provisions. Moreover, the options are not transferable and the beneficiaries are precluded, as insiders, from short selling the firm's stock according to section 16-c of the Securities Exchange Act. This prohibition stands for a hedging restriction.

As pointed out earlier, one of the strengths of this research is the quality of the dataset used. As far as I know, this research is the most comprehensive empirical study on employee stock option exercise patterns in the American context since it uses the largest and the most diversified sample ever used in the literature.

\section{Table-1: Data sample features}

This table includes some descriptive information about the data sample. This sample includes 35,086 exercise transactions made by 7,125 employees in 12 US companies representing 9 different industries. It involves 542 stock option plans granted during the period from 1983 to 2006. The firms market capitalizations range from $\$ 323 \mathrm{M}$ to $\$ 40524 \mathrm{M}$ as at $12 / 31 / 2006$. The plans are standard stock option contracts (i.e. Bermudian-style options) that do not include performance-related vesting provisions. Their vesting is either immediate or achieved after specified periods varying from 2 to 9.5 years. The options maturities are from 5 to 10.5 years.

\begin{tabular}{|c|c|c|c|c|c|c|c|c|c|c|}
\hline Company & $\begin{array}{l}\text { Industry } \\
\text { (Sector) }\end{array}$ & $\begin{array}{c}\text { Market } \\
\text { Capitalization } \\
(*)\end{array}$ & $\begin{array}{l}\text { \# of } \\
\text { plans }\end{array}$ & $\begin{array}{l}\text { \# of exercise } \\
\text { transactions }\end{array}$ & $\begin{array}{c}\# \text { of } \\
\text { cancellations } \\
\text { and } \\
\text { expirations } \\
\end{array}$ & $\begin{array}{c}\text { Exercise } \\
\text { transactions } \\
\text { periods }\end{array}$ & $\begin{array}{l}\text { Grants } \\
\text { periods }\end{array}$ & $\begin{array}{l}\text { Vesting } \\
\text { periods }\end{array}$ & $\begin{array}{c}\text { \# of } \\
\text { involved } \\
\text { countries }\end{array}$ & $\begin{array}{c}\text { Options } \\
\text { terms }\end{array}$ \\
\hline $\mathrm{F} 1$ & $\begin{array}{l}\text { Financial } \\
\text { Guarantee } \\
\text { Insurance }\end{array}$ & 1601 & 23 & 443 & 232 & $\begin{array}{l}02 / 1998 \text { to } \\
12 / 2005\end{array}$ & $\begin{array}{c}01 / 1997 \\
\text { to } \\
01 / 2003 \\
\end{array}$ & $\begin{array}{c}\text { Immediate, } \\
3 \text { and } 4 \\
\text { years }\end{array}$ & 4 & 7 years \\
\hline $\mathrm{F} 2$ & $\begin{array}{c}\text { Gas- } \\
\text { Distribution }\end{array}$ & 4275 & 86 & 1835 & 2079 & $\begin{array}{c}06 / 1995 \text { to } \\
03 / 2006\end{array}$ & $\begin{array}{c}02 / 1993 \\
\text { to } \\
11 / 2005\end{array}$ & 3 years & 1 & 10 years \\
\hline F3 & $\begin{array}{c}\text { Retail- } \\
\text { Discount }\end{array}$ & 40524 & 245 & 5740 & 11659 & $\begin{array}{l}\text { 03/1991 to } \\
11 / 2005\end{array}$ & $\begin{array}{c}01 / 1999 \\
\text { to } \\
11 / 2000\end{array}$ & $\begin{array}{l}\text { Immediate } \\
\text { to } 9.5 \\
\text { years }\end{array}$ & 1 & 10 years \\
\hline F4 & $\begin{array}{l}\text { Retail-Drug } \\
\text { Store }\end{array}$ & 38898 & 5 & 6731 & 1281 & $\begin{array}{c}06 / 1994 \text { to } \\
06 / 2005\end{array}$ & $\begin{array}{c}10 / 1992 \\
\text { to } \\
10 / 1996\end{array}$ & 2 years & 1 & 10 years \\
\hline F5 & $\begin{array}{l}\text { Aerospace- } \\
\text { Defense }\end{array}$ & 12432 & 33 & 13981 & 11871 & $\begin{array}{l}05 / 1996 \text { to } \\
04 / 2006\end{array}$ & $\begin{array}{c}05 / 1995 \\
\text { to } \\
02 / 2005\end{array}$ & $\begin{array}{c}2 \text { and } 3 \\
\text { years }\end{array}$ & 1 & 10 years \\
\hline F6 & $\begin{array}{l}\text { Electric- } \\
\text { Integrated }\end{array}$ & 323 & 21 & 214 & 432 & $\begin{array}{l}05 / 2001 \text { to } \\
07 / 2005\end{array}$ & $\begin{array}{c}05 / 2000 \\
\text { to } \\
02 / 2004\end{array}$ & 3 years & 1 & 10 years \\
\hline F7 & $\begin{array}{l}\text { Pollution } \\
\text { Control }\end{array}$ & 8088 & 14 & 267 & 247 & $\begin{array}{l}06 / 2000 \text { to } \\
09 / 2005\end{array}$ & $\begin{array}{c}03 / 1997 \\
\text { to } \\
01 / 2004 \\
\end{array}$ & $\begin{array}{c}\text { Immediate, } \\
4 \text { and } 5 \\
\text { years }\end{array}$ & 1 & 10 years \\
\hline F8 & $\begin{array}{l}\text { Distribution- } \\
\text { Wholesale }\end{array}$ & 751 & 14 & 632 & 1025 & $\begin{array}{l}03 / 1996 \text { to } \\
09 / 2005\end{array}$ & $\begin{array}{c}03 / 1995 \\
\text { to } \\
04 / 2004\end{array}$ & $\begin{array}{l}\text { Immediate } \\
\text { to } 3 \text { yeas }\end{array}$ & 1 & $\begin{array}{c}5 \text { and } \\
10 \text { years }\end{array}$ \\
\hline F9 & $\begin{array}{l}\text { Gambling } \\
\text { (Non-Hotel) }\end{array}$ & 3030 & 22 & 474 & 862 & $\begin{array}{l}11 / 1993 \text { to } \\
03 / 2005\end{array}$ & $\begin{array}{c}02 / 1993 \\
\text { to } \\
10 / 2003\end{array}$ & $\begin{array}{c}\text { Immediate, } \\
4 \text { and } 5 \\
\text { years }\end{array}$ & 1 & 10 years \\
\hline F10 & $\begin{array}{l}\text { Instruments- } \\
\text { Controls }\end{array}$ & 10427 & 24 & 463 & 952 & $\begin{array}{l}06 / 1998 \text { to } \\
04 / 2005\end{array}$ & $\begin{array}{c}10 / 1996 \\
\text { to } \\
08 / 2003\end{array}$ & 5 years & 28 & $\begin{array}{c}6,10 \\
\text { and } \\
10.5 \\
\text { years }\end{array}$ \\
\hline F11 & $\begin{array}{l}\text { Property- } \\
\text { Casualty } \\
\text { Insurance }\end{array}$ & 1798 & 46 & 2624 & 2421 & $\begin{array}{c}03 / 1985 \text { to } \\
08 / 2005\end{array}$ & $\begin{array}{c}02 / 1983 \\
\text { to } \\
05 / 2004\end{array}$ & $\begin{array}{c}\text { Immediate, } \\
2,3 \text { and } 6 \\
\text { years }\end{array}$ & 1 & 10 years \\
\hline F12 & $\begin{array}{l}\text { Electric- } \\
\text { Integrated }\end{array}$ & 27512 & 9 & 1682 & 16149 & $\begin{array}{c}09 / 2004 \text { to } \\
02 / 2007\end{array}$ & \begin{tabular}{|c|}
$02 / 2004$ \\
to \\
$02 / 2006$
\end{tabular} & $\begin{array}{l}\text { Immediate } \\
\text { and } 3 \\
\text { years }\end{array}$ & 1 & 10 years \\
\hline
\end{tabular}

(*) Market Capitalization at 12/31/2006 (in millions of \$), except for E7 (data at 07/06/2006 instead). 


\subsubsection{Construction of the variables}

The parameterization of the CPT model relies on two types of input variables. The first set of variables characterizes the exercise policy of the employee. These are constructed from the data sample of option exercises at the US companies described in the previous section. The second set is specific to the economy of the stock option contracts. The variables comprising this set are estimated based on data from the Bloomberg proprietary financial database.

The first set of variables comprises the exercise stock price ratio, the lifetime of the option and the cancellation rate. These variables are directly computed from the data sample described earlier. In particular, the cancellation rates were determined at the individual level (i.e. for each holder and for each plan), on an annual basis, as the number of the yearly forfeited and out-of-the money expired options dividend by the total number of options granted with respect to a given plan. The final share price levels were assimilated to the split-adjusted expiration date closing stock price normalized by the strike price. These ratios were computed using the share price data from the Bloomberg database. Note that for the specific case of the outstanding plans (representing roughly 11,750 exercise transactions), I used the closing share prices on October $29^{\text {th }} 2010$ as proxies for the final share prices levels, except for the firm F7, the closing share price as of July $6^{\text {th }} 2006$ was used instead. In addition, I must emphasize that, opposite to Carpenter (2008), average variables are not weighted by the sizes of exercise transactions because this conducts to introducing a bias in the variables estimates due to overweighting some exercise behaviors (i.e. employees with largest stock option holdings) against others.

The second type of variables is mainly constructed based on financial data from the Bloomberg proprietary database, except from variables proper to the stock option contract design, namely the maturity dates and the vesting periods. These were drawn from the exercises data sample. Specifically, I used as a proxy of the risk free interest rate the prevailing US T-bills rates at the inception of each plan. Similar to Carpenter (1998), I used an equity risk premium of $7 \%$, which is roughly the arithmetic average premium over the period from 1958 to 2005 reported in Ibbotson Associates (2006). I computed the expected stock price return using the CAPM: the risk free rate plus the risk premium times the beta of the company at the grant date. The latter is computed using daily stock price returns over the 1-year period prior to the grant date against the relevant benchmark ${ }^{13}$. Moreover, dividend yields were estimated using recorded dividend data over the year prior to the exercise date. In the same manner, stock return volatilities were computed over the 360-day period prior to the exercise date.

\footnotetext{
${ }^{13}$ Depending on the company listing stock exchange, betas were estimated either against the NYSE Composite index or the NASDAQ Composite index.
} 
Table-2 presents summary statistics on these variables. Panel-A exhibits descriptive statistics showing that, on average, the stock options vested after 1.80 years and were exercised after 4.30 years at stock prices representing 2.46 times the strike prices. Actually, average figures could be seen as variables describing exercise patterns in a representative company. Such a company would have then a volatility of $31.59 \%$, a $2.15 \%$ dividend yield, an expected stock return almost equal to $13 \%$ and an effective overall stock price performance equal to $111 \%$. Moreover, it is worth mentioning that the share price data covers the 2007-2008 crisis period, hence the maximum volatility of $94.03 \%$ and the minimum performance of $-99 \%$. These figures pertain to firm F1 that belongs to the financial industry. This company becomes a penny stock during the crisis period. Furthermore, the cancellation rates in the sample range from $0.00 \%$ to $28.57 \%$ with a mean of $6.30 \%$ which is lower than the mean cancellation rate in Carpenter (1998) equal to 7.30\%. Surprisingly, the median cancellation rate in the sample is identical to that in Bettis et al. (2005). On the other hand, the mean variables characterizing the stock option contract economy in Carpenter (1998) are noticeably close to ours. However, the variables describing exercise patterns in her sample show, by contrast, that exercises tend to occur latter (mean option lifetime of 5.83) at a higher stock price (mean exercise stock price ratio of 2.75).

Table-2: Variables summary statistics

This table reports summary statistics on the variables used in this empirical study. These include two types of variables: variables describing exercise patterns and variables characterising the economy of the stock option contract. The option exercise variables are constructed from a data sample of option exercises at 12 US companies. This set of variables includes the exercise stock price ratio " $S_{\tau}$ ", the lifetime of the option " $\tau$ ", the cancellation rate " $\eta$ " and the final stock price ratio " $S_{T}^{*}$ ". The variables specific to the economy of the stock option contract include the maturity of the option " $T$ ", the vesting period " $t v$ ", the stock dividend yield " $q$ ", the stock price returns volatility " $\sigma$ ", the stock price Beta " $\beta$ ", the stock price expected return " $\mu$ " and the risk free rate " $r$ ".

\begin{tabular}{|c|c|c|c|c|c|c|c|c|c|c|c|}
\hline & $T$ & $S_{\tau}$ & $\tau$ & $t_{v}$ & $q$ & $\sigma$ & $S_{T}^{*}$ & $\beta$ & $r$ & $\mu$ & $\eta$ \\
\hline \multicolumn{12}{|l|}{ Panel A: Descriptive statistics } \\
\hline Maximum & 10.50 & 49.39 & 10.01 & 9.50 & $9.94 \%$ & $94.03 \%$ & 51.57 & 1.12 & $7.00 \%$ & $14.41 \%$ & $28.57 \%$ \\
\hline Minimum & 5.00 & 1.01 & 0.06 & 0.00 & $0.00 \%$ & $12.46 \%$ & 0.01 & 0.40 & $4.44 \%$ & $7.25 \%$ & $0.00 \%$ \\
\hline Average & 9.90 & 2.46 & 4.30 & 1.80 & $2.15 \%$ & $31.59 \%$ & 2.11 & 0.80 & $5.50 \%$ & $12.59 \%$ & $6.30 \%$ \\
\hline Median & 10.00 & 1.66 & 3.63 & 2.00 & $1.36 \%$ & $29.93 \%$ & 1.38 & 0.80 & $5.35 \%$ & $11.52 \%$ & $4.11 \%$ \\
\hline Standard deviation & 0.66 & 1.96 & 2.46 & 0.72 & 0.02 & $10.82 \%$ & 3.17 & 0.24 & $0.81 \%$ & $2.18 \%$ & $24.30 \%$ \\
\hline \multicolumn{12}{|l|}{ Panel B: Correlations } \\
\hline$T$ & 1.000 & & & & & & & & & & \\
\hline$S_{\tau}$ & 0.075 & 1.000 & & & & & & & & & \\
\hline$\tau$ & 0.025 & 0.504 & 1.000 & & & & & & & & \\
\hline$t_{v}$ & -0.084 & 0.147 & 0.303 & 1.000 & & & & & & & \\
\hline$q$ & -0.014 & -0.155 & -0.180 & 0.129 & 1.000 & & & & & & \\
\hline$\sigma$ & 0.078 & -0.033 & -0.270 & -0.021 & -0.194 & 1.000 & & & & & \\
\hline
\end{tabular}

Panel-B provides the cross-correlations of the variables. As expected, the correlations of the vesting period " $t_{v}$ " with the time to exercise " $\tau$ " and with the exercise price ratio " $S_{\tau}$ " are positive, which is consistent with the principle that options with longer vesting periods tend to be exercised later and deeper in the money. At the opposite, the exercises seem to occur latter and at higher stock 
price levels in the companies with lower dividend yields since both " $S_{\tau}$ " and " $\tau$ " are negatively correlated to " $q$ ". This is consistent with the American option rational exercise theory. Also, the volatility " $\sigma$ " is negatively correlated to the exercise time (while insignificantly correlated to the exercise price ratio) denoting an exercise behavior imbued with risk aversion (Huddart, 1994; Marcus and Kulatilaka, 1994; Carpenter, 1998).

\subsection{The methodology}

\subsubsection{The models calibrations}

If the subjective values of the stock options where observable, one would estimate the preferences parameters implied by these values (i.e. choose the parameters that make the option values yielded by the model best match observed prices). Instead, I calibrate each model to best match the values of the variables characterizing exercise behavior, namely the exercise price ratio, the option lifetime and the cancellation rate. Following Carpenter (1998), I started by performing a base case calibration consisting in finding the set of unknown parameters " $P$ " that make the models predictions best fit the average values of the observed exercise variables (i.e. fit a representative company whose variables are equal to the sample mean values). In order to check the accuracy of the base case calibrations under which the models will be compared, I performed some alternative calibrations for the CPT model and the EU model. All the calibrations are performed based on a monthly time-step setting (i.e. monthly stock price tree where exercise decisions are made at each node).

\subsubsection{The CPT model}

For the CPT model, the set of the unknown parameters that need to be estimated is " $P=\left\{a, \rho, p_{e}, y\right\}$ ". Some of these parameters, namely " $a$ " and " $\rho$ ", describe the preferences of a representative employee. The other parameters characterizing his risk preferences (i.e. the value function curvature and the loss aversion parameters) are set at their experimental estimates from the

CPT (Tversky and Kahneman, 1992): “ $\hat{\lambda}=2.25$ ” and " $\hat{\alpha}=0.88$ ”. I used the methodology in Carpenter (1998) that consists in the minimization of a cost function " $\varepsilon\left(a, \rho, p_{e}, y\right)$ " measuring the distance between mean observations and the model predictions. As we can notice from the following optimization problem, the function gives more weight to the parameters that has less cross-sectional dispersion:

$$
\begin{aligned}
& P=\underset{\substack{a, \rho, p_{e}, y \\
\operatorname{ArgMin}}}{\operatorname{ar}}\left(a, \rho, p_{e}, y\right) \\
& \varepsilon\left(a, \rho, p_{e}, y\right)=\frac{\left(\bar{\tau}-\hat{\tau}\left(a, \rho, p_{e}, y\right)\right)^{2}}{\sigma_{\tau}{ }^{2}}+\frac{\left(\bar{S}_{\tau}-\hat{S}_{\tau}\left(a, \rho, p_{e}, y\right)\right)^{2}}{\sigma_{S_{\tau}}{ }^{2}}+\frac{\left(\bar{\eta}-\hat{\eta}\left(a, \rho, p_{e}, y\right)\right)^{2}}{\sigma_{\eta}{ }^{2}}
\end{aligned}
$$


Where the hats represent the model predictions, the bars are the sample averages and the denominators are their sample variances.

Panel-1 of table- 3 exhibits the parameters estimates ${ }^{14}$ yielded by the base case calibration of the CPT model. According to the $\chi^{2}$-test, the calibration error is statistically insignificant at the $1 \%$ level, which means that the calibration results are statistically significant. The results show that the representative employee would set the reference point quite high at a level equivalent to an annual share price performance of $31.46 \%$. Moreover, there is a $22 \%$ probability for him to leave the company for a cash amount of $\$ 0.38$ per each option held. This amount is surprisingly close to the BS value of the option granted to him (\$0.39). Another interesting result yielded by the base case calibration is the probability weighting parameter estimate $(\hat{a}=0.69)$ that lies within the range of the experimental estimates ${ }^{15}$. Actually, experimental literature show that this parameter may range from 0.56 to 0.71 with an average value of roughly 0.65 . In addition, this result is consistent with Polkovnichenko and Zhao (2009) finding that the Kahneman and Tversky probability weighting function parameter implied by S\&P options prices is close to 0.7 during the periods when they found empirical support for the inverse S-shaped probability weighting function (i.e. weighting function emphasizing risk in the tails of a distribution).

Panel-1 also includes the results of alternative calibrations. Except from calibration \#2, the purpose of each alternative is to check the robustness of the base case calibration with respect to each of the four parameters. Calibration \#1 consists in setting the probability weighting parameter at the average experimental estimate of 0.65 and estimating the remaining parameters. The aim of calibration \#2 is to calibrate a variant of the model excluding the non-market factors. It relies on the neutralization of the effect of the exit probability, by setting this one at zero, and the calibration of the model for all the preferences-related parameters. The set of parameters that need to be estimated in this case is " $P=\{a, \rho, \lambda, \alpha\}$ ”. The alternative calibration \#3 aims to assess the performance of the calibration of the CPT model relative to that of the EU model assuming the same non-market factors levels. It consists in setting the exit probability and the leaving amount at their respective estimates from the EU model base case calibration (see panel-2). Alternatives \#4 and \#5 are focused on the sensitivity of the calibration performance to the reference point parameter. They are performed by setting the reference

\footnotetext{
${ }^{14}$ The optimization problem was solved numerically based on a Monte Carlo approach. This method consists in randomly drawing values of the parameters within their definition domains. The drawn values are saved if they yield lower error value than the previous one. This process is retrieved until either the error threshold is hit or the maximum number of trials is achieved. The error threshold and the number of trials used are respectively $10^{-5}$ and 10,000 .

${ }^{15}$ Tversky and Kahneman (1992) got 0.65 on average ( " $a=0.61$ " for gains and " $b=0.69$ " for losses). These results are corroborated by Abdellaoui's (2000) findings ( " $a=0.60$ " for gains and " $b=0.70$ " for losses, hence an average of 0.65). In addition, Camerer and Ho (1994) obtained " $a=0.56$ " for gains whereas Gonzales and Wu (1996) and Bleichrodt and Pinto (2000) found " $a=0.71$ " and " $a=0.67$ " respectively.
} 
point parameter to respectively the average expected stock price return $(\bar{\mu}=12.59 \%)$ and the BS value of the average option contract as a percentage of the stock price at inception (39.41\%).

As we can see from the $\chi^{2}$-test $p$-values in panel-1, all the calibrations are statistically significant at the $1 \%$ level. Relying on the calibration errors, the base case calibration, alternative calibrations \#1, \#2, \#3 and \#4 are the best performing and have comparable errors. Calibration \#5 turns out to be the least performing and, therefore, the worst fitting average data. Calibration \#2 results show that the sole CPT-based preferences factors could be sufficient to explain average exercise patterns. However, contrasting with the experimental literature, the results show also that the representative employee has

to be more loss-averse than experimental estimates $(\hat{\lambda}=4.70>2.25)$ for his exercise behavior to best fit average data. His value function has also to be more curved than what experimental estimates indicate $(\hat{\alpha}=0.26<0.88)$. Besides, given that the probability weighting parameter " $a$ " estimate under this calibration is close to 1 (i.e. extremely weak probability weighting effect), inconsistently, this feature of preferences turns out to be irrelevant with regards to exercise behavior patterns in the absence of non-market factors. On the other hand, the probability weighting parameter estimates yielded by the other calibrations are stable around 0.66 , which remains comparable to the experimental estimates. It is worth noticing that the results from calibration \#1 show that setting this parameter at the mean experimental estimate is neutral to the performance of the calibration and do not affect the other parameters estimates. Further, the value of the exit probability " $p$ " is stable across all the calibrations, supporting the robustness of the base case calibration with respect to this parameter. The same comment should be formulated about the estimates of the leaving amount parameter " $y$ ". Furthermore, the reference point estimates are comparable among the base case calibration, calibration $\# 1$ and \#3. Specifically, the calibration performance is not significantly improved neither under the assumption that the representative employee sets his reference point at the expected share price returns (calibration \#4) nor under that where the reference point meets the BS value of the option at inception (calibration \#5). In summary, these results, along with the remark that the model predictions are quite steady across all the calibrations, plead in favor of the robustness of the base case calibration.

\subsubsection{The EU model}

I used the same methodology to calibrate the EU model. The optimization problem in the base case calibration is described in (10). The numerical resolution of this problem leads to estimating the set of unknown parameters " $P=\left\{w, p_{e}, y\right\}$ ”. Similar to Carpenter (1998) and Bettis et al.(2005), I set the risk aversion coefficient equal to 2 .

$$
P=\underset{w, p_{e}, y}{\operatorname{ArgMin}} \varepsilon\left(w, p_{e}, y\right)
$$


$\varepsilon\left(w, p_{e}, y\right)=\frac{\left(\bar{\tau}-\hat{\tau}\left(w, p_{e}, y\right)\right)^{2}}{\sigma_{\tau}{ }^{2}}+\frac{\left(\bar{S}_{\tau}-\hat{S}_{\tau}\left(w, p_{e}, y\right)\right)^{2}}{\sigma_{S_{\tau}}{ }^{2}}+\frac{\left(\bar{\eta}-\hat{\eta}\left(w, p_{e}, y\right)\right)^{2}}{\sigma_{\eta}{ }^{2}}$

The results of the base case calibration are reported in panel-2 of table- 3 . As we can see from the $\chi^{2}$-test p-value, this calibration is significant at the 5\% level. The parameters estimates imply that in order to best match the sample average exercise patterns, the representative employee outside wealth would have to be slightly more than one time the value of the stock underlying his granted options. These results also imply that the employee would have a $27 \%$ chance to leave the company and receive an amount of $\$ 0.71$ per granted option. Note that the exit probability estimate is close to that of the CPT model base case calibration, while the leaving amount estimate is almost 2 times that in the CPT model. Moreover, while the base case calibration in Carpenter (1998) better matches the mean data, the values of the outside wealth " $w$ " and the leaving amount " $y$ " are too large (342 and 132 times the value of the underlying stock respectively), which may seem troubling in the sense that the model predicts that the representative executive is very wealthy. The outside wealth estimate in our base case calibration is still however comparable to that in Bettis et al. $(2005)(\hat{w}=2.1)$ despite the fact that their calibration is based on median data. Actually, although our estimate is lower, it is consistent with the fact that our sample is larger and includes exercises for both non executives and executives populations. On the other hand, the EU model base case calibration is less performing in fitting the average data than the CPT model calibration based on the same non-market factors values (i.e. alternative calibration \#3).

Panel-2 also reports the results of alternative calibrations. Alternative \#1 and \#4 are focused on the robustness with respect to " $y$ " and " $w$ " respectively. They consist in setting these parameters at their upper boundaries and estimating the other unknown parameters. The two upper boundaries were arbitrary chosen. Similar to that in the CPT model, alternative \#2 aims to calibrate a non-market factors-neutral version of the model in order to assess the ability of the sole preferences factors to match with the mean exercise data. The set of parameters that needs to be estimated under this calibration becomes then " $P=\{\gamma, w\}$ ". Alternative calibration \#3 aims to assess the performance of the calibration of the EU model relative to that of the EA model assuming the same exit probability level ( $\left.\hat{p}_{e}=0.36\right)$.

As we can see from the calibration errors figures in panel-2, alternative \#2 is the best performing in the sense that it best fits the average data. It is significant at the $1 \%$ level while the other alternatives are only significant at the $5 \%$ level. The parameters estimates yielded by this calibration show that in case there is no chance for the representative employee to quit the company, his risk-aversion would have to be quite high $(\hat{\gamma}=6.28)$ so that his exercise behavior best fits the average exercise data. The 
model predicts under this calibration that the exercise will occur slightly latter and deeper in the money compared to the other calibrations predictions. Moreover, alternative \#1 shows that the calibration is robust with respect to " $y$ " since it does not affect the model predictions and the estimates of the other parameters. Also, we learn from alternative \#3 that, assuming the same exit probability, the EU model over performs the EA model in fitting the average data (see panel-3). However, this calibration yields higher estimates of " $y$ " and " $w$ ". This means that the higher the probability for the employee to leave the company, the higher should be his outside wealth and the amount he receives when leaving so that his exercise behavior best matches the average exercise in the sample. Conversely, as confirmed by the estimates yielded by alternative calibration \#4, the wealthier the employee, the higher the implied exit probability and the leaving amount. Finally, based on these results regarding the alternative calibrations and the noticeable finding that the model predictions are stable across all calibrations, we can deduce that the base case calibration of EU model is robust.

\subsubsection{The EA model}

The parameter of interest in the calibration of the EA model is the exit probability, thus “ $P=\left\{p_{e}\right\}$ ". In the same way as previously done, the calibration process relies on the following optimization problem:

$$
\begin{aligned}
& P=\underset{p_{e}}{\operatorname{ArgMin}} \mathcal{E}\left(p_{e}\right) \\
& \varepsilon\left(p_{e}\right)=\frac{\left(\bar{\tau}-\hat{\tau}\left(p_{e}\right)\right)^{2}}{\sigma_{\tau}{ }^{2}}+\frac{\left(\bar{S}_{\tau}-\hat{S}_{\tau}\left(p_{e}\right)\right)^{2}}{\sigma_{S_{\tau}}{ }^{2}}+\frac{\left(\bar{\eta}-\hat{\eta}\left(p_{e}\right)\right)^{2}}{\sigma_{\eta}{ }^{2}}
\end{aligned}
$$

As we can see from the calibration results reported in panel-3 of table-3, the calibration is significant at the 5\% level. As expected, the EA model underperforms the two previous competing models in fitting the average exercise data since the calibration error is the highest among all errors obtained in the base case calibrations. Note that the exit probability estimate yielded by the calibration ( $\left.\hat{p}_{e}=0.36\right)$ is much higher than that got by Carpenter (1998) as well as that in Bettis et al. (2005) (0.11 and 0.22 respectively). 
Table-3: Calibrations results

This table presents the results of the calibrations of the three competing models. Panel-1 exhibits figures specific to the calibration of the CPT model. Panel-2 and Panel-3 report results of the calibration of the EU model and the EA model respectively. The upper block of each panel includes the parameters estimates yielded by of the calibrations $(\hat{P})$. The middle block comprises the calibrations errors " $\varepsilon$ " and the related ${ }^{2} N$ significance test $\mathrm{p}$-values where the null hypothesis is "H0: $\varepsilon=0$ ". The bottom block reports the model forecasts of the exercise variables implied by each calibration.

\begin{tabular}{lcccccc}
\hline \multirow{2}{*}{ Calibration outputs } & $\begin{array}{c}\text { Base case } \\
\text { Calibration }\end{array}$ & $\begin{array}{c}\text { Alternative } \\
\text { calibration } \\
\# 1\end{array}$ & $\begin{array}{c}\text { Alternative } \\
\text { calibration } \\
\# 2\end{array}$ & $\begin{array}{c}\text { Alternative } \\
\text { calibration } \\
\# 3\end{array}$ & $\begin{array}{c}\text { Alternative } \\
\text { calibration } \\
\# 4\end{array}$ & $\begin{array}{c}\text { Alternative } \\
\text { calibration } \\
\# 5\end{array}$ \\
\hline
\end{tabular}

Panel-1: CPT Model

\begin{tabular}{ccccccc} 
Parameters: $\hat{P}$ & \multicolumn{1}{l}{} \\
\hline$\hat{p}_{e}$ & 0.22 & 0.22 & - & 0.27 & 0.25 & 0.21 \\
$\hat{\rho}$ & $31.46 \%$ & $29.55 \%$ & $20.25 \%$ & $24.62 \%$ & $12.59 \%$ & $39.41 \%$ \\
$\hat{y}$ & 0.38 & 0.31 & - & 0.71 & 0.29 & 0.28 \\
$\hat{a}$ & 0.690 & 0.650 & 0.910 & 0.630 & 0.700 & 0.660 \\
$\hat{\lambda}$ & 2.25 & 2.25 & 4.70 & 2.25 & 2.25 & 2.25 \\
$\hat{\alpha}$ & 0.88 & 0.88 & 0.26 & 0.88 & 0.88 & 0.88 \\
\hline Calibration error: $\boldsymbol{\varepsilon}(\boldsymbol{a}, \boldsymbol{\rho}, \boldsymbol{q}, \boldsymbol{y})$ & 0.004 & 0.004 & 0.002 & 0.006 & 0.002 & 0.017 \\
${ }^{2} \boldsymbol{N}$ test $(\boldsymbol{p}$-value $)$ & 1.000 & 1.000 & 1.000 & 1.000 & 1.000 & 0.999 \\
\hline$\hat{S}$ & 2.47 & 2.42 & 2.46 & 2.52 & 2.44 & 2.52 \\
$\hat{\tau}$ & 4.42 & 4.41 & 4.24 & 4.24 & 4.36 & 4.61 \\
$\hat{\eta}$ & $7.23 \%$ & $7.08 \%$ & $5.36 \%$ & $7.82 \%$ & $7.20 \%$ & $7.01 \%$ \\
\hline \hline
\end{tabular}

Panel-2: EU Model

Parameters: $\hat{P}$

\begin{tabular}{cccccc} 
Parameters: & $P$ & & & \\
\hline$\hat{\gamma}$ & 2.00 & 2.00 & 6.28 & 2.00 & 2.00 \\
$\hat{w}$ & 1.14 & 1.33 & 3.84 & 8.58 & 500.00 \\
$\hat{p}_{e}$ & 0.27 & 0.30 & - & 0.36 & 0.50 \\
$\hat{y}$ & 0.71 & 25.00 & - & 0.90 & 1.33 \\
\hline Calibration error: $\boldsymbol{\varepsilon}(\boldsymbol{\gamma}, \boldsymbol{w}, \boldsymbol{q}, \boldsymbol{y})$ & 0.130 & 0.141 & 0.103 & 0.139 & 0.146 \\
${ }^{2} \boldsymbol{N}$ test $(\boldsymbol{p}$-value $)$ & 0.988 & 0.986 & 0.992 & 0.987 & 0.986 \\
\hline$\hat{S}_{\tau}$ & 1.69 & 1.70 & 1.88 & 1.74 & 1.67 \\
$\hat{\tau}$ & 4.27 & 4.43 & 4.48 & 4.61 & 4.48 \\
$\hat{\eta}$ & $7.13 \%$ & $8.06 \%$ & $5.36 \%$ & $7.33 \%$ & $7.66 \%$ \\
\hline \hline
\end{tabular}

Panel-3: EA Model

Parameters: $\hat{P}$

\begin{tabular}{cc}
\hline$\hat{p}_{e}$ & 0.36 \\
\hline Calibration error: $\varepsilon(\boldsymbol{q})$ & 0.163 \\
${ }^{\left.{ }^{\boldsymbol{N}} \text { test } \text { (p-value }\right)}$ & 0.983 \\
\hline$\hat{S}_{\tau}$ & 1.75 \\
$\hat{\tau}$ & 4.68 \\
$\hat{\eta}$ & $8.30 \%$ \\
\hline
\end{tabular}

\subsubsection{The criteria of the models comparison}

In order to compare the ability of the models to predict exercise patterns in the sample based on their respective base case calibrations, I computed the models forecasts of the exercise stock price ratio and the lifetime of the option for each of the 35,086 exercise transactions in the sample. Beyond 
the information implied by the base case calibrations (i.e. embedded in the preferences parameters), these forecasts integrate specific information about the exercised stock options and the prevailing market conditions, namely the vesting period, the maturity date, the expected stock price return, the stock price volatility, the dividend yield, the risk free rate and the final stock price level. Consistent with the calibrations setting, the computations were performed using monthly time-steps. Formally, for a given transaction " $i$ ", with $i \in\{1 ; 2 ; \ldots ; 35,086\}$, the related predictions are assimilated to the following conditional expectations:

$$
\begin{gathered}
\hat{S}_{\tau, i}=I E^{p}\left(S_{\tau, i} \mid P, t_{v, i}, T_{i}, \mu_{i}, \sigma_{i}, q_{i}, r_{i}, s_{T, i}^{*}\right) \\
\hat{\tau}_{i}=I E^{p}\left(\tau_{i} \mid P, t_{v, i}, T_{i}, \mu_{i}, \sigma_{i}, q_{i}, r_{i}, s_{T, i}^{*}\right)
\end{gathered}
$$

Further, to assess the performance of each model in explaining the cross-sectional variations in the exercise variables, I used the following metrics:

- $\quad$ Mean Squared Percentage Errors (MSPE):

$$
\begin{aligned}
& \mathcal{E}_{s}=\frac{1}{n} \sum_{i=1}^{n}\left[\frac{\left(S_{\tau, i}-\hat{S}_{\tau, i}\right)}{\hat{S}_{\tau, i}}\right]^{2} \\
& \mathcal{E}_{\tau}=\frac{1}{n} \sum_{i=1}^{n}\left[\frac{\left(\tau_{i}-\hat{\tau}_{i}\right)}{\hat{\tau}_{i}}\right]^{2}
\end{aligned}
$$

- $\quad$ Mean Absolute Percentage Errors (MAPE):

$$
\begin{gathered}
\xi_{s}=\frac{1}{n} \sum_{i=1}^{n} \frac{\left|S_{\tau, i}-\hat{S}_{\tau, i}\right|}{\hat{S}_{\tau, i}} \\
\xi_{\tau}=\frac{1}{n} \sum_{i=1}^{n} \frac{\left|\tau_{i}-\hat{\tau}_{i}\right|}{\hat{\tau}_{i}}
\end{gathered}
$$

With $n=35,086$.

- Adjusted $\mathrm{R}^{2}$ from the following OLS regressions:

$$
\begin{gathered}
S_{\tau, i}=\alpha_{s}+\beta_{s} \hat{S}_{\tau, i}+\tilde{z}_{s, i} \\
\tau_{i}=\alpha_{\tau}+\beta_{\tau} \hat{\tau}_{i}+\tilde{z}_{\tau, i}
\end{gathered}
$$


The most performing model should have the lowest MSPE and/or MAPE and the highest $\mathrm{R}^{2}$. In order to check whether the spreads between the metrics yielded by each model are statistically significant, I used two different statistical tests. The first one is the non parametric signed-rank test of Wilcoxon. The second one is the impaired Student's t-test.

I reiterated the same approach to compare the performance of the models calibrations ignoring the non-market factors (i.e. alternative calibrations \#2). The purpose here is to figure out which model is the best doing in predicting exercise patterns assuming the employees are "stuck" with their companies. This also boils down to identifying the risk preferences specification that better explains the exercise behavior (that of the EUT or that of the CPT instead).

\subsection{The results}

Table- 4 presents the results of the empirical analysis based on the base case calibrations. The results are reported within two blocks. The left-hand block includes the forecast errors metrics (i.e. MSPE and MAPE) and the related statistical tests p-values. Note that the "combined" metric is nothing more than the sum of the option lifetime metric and that of the exercise stock price ratio. The right-hand block contains the OLS regression statistics in particular the adjusted $\mathrm{R}^{2}$, the slope " $\alpha_{i \in\{s, \tau\}}$ " and the intercept " $\beta_{i \in\{s, \tau\}}$ " of the model and their respective t-test p-values.

Panel-1 figures are about the CPT model. Consistent with our hypothesis stated earlier, the CPT model outperforms the two competing models since it yields forecast errors below the smallest of any of the forecast errors yielded by the other models. Although the Wilcoxon test indicates for the exercise stock price ratio that, mainly, the CPT model individual Squared Percentage Errors (SPE) rank above those of the EU model in the sample, the differences between all forecast errors mean values are significant at the $1 \%$ level according to the Student's t-test. In addition, the CPT model has the highest $\mathrm{R}^{2}$ (up to seven times that of the EU model) and its regression parameters are significant at the $1 \%$ level. Therefore relying on the base case calibrations, the CPT model shows a significant improvement over the EU model and the EA model in terms of both the size of the forecast errors and the variance explanatory power of the OLS regression.

The empirical analysis results regarding the EU model are reported in panel-2. As we can see from the figures, this model has the highest MSPE and MAPE. It also has the lowest $\mathrm{R}^{2}$ despite the significance of its regression parameters. Therefore, it turns out that the EU model is the worst performing model under the base case calibration, even when compared to the EA model. In fact, the differences between the forecast errors of the two models are meaningful in that the t-test is significant at the $1 \%$ level. This finding contrasts to the results in Carpenter (1998) showing that the EU model performs as well as the EA model. It is also in stark contrast with Bettis et al. (2005) findings that, compared to the EU model, the EA model produces exercise behavior forecasts that are further away 
from the observed values. Moreover, the EU model yielded forecast performance metrics, including forecast errors and regression statistics, are less satisfactory than those got by Carpenter (1998). The EA model has also bad performance indicators compared to those in Carpenter (1998) (see panel-3). At first sight, these differences could be attributed to the differences among the data sample characteristics.

\section{Table-4: Models comparison under the base case calibrations}

This table presents the results of the comparison of the models under their respective base case calibrations. Mean variables of interest in this analysis are the exercise stock price ratio " $S_{\tau}$ " and the lifetime of the option " $\tau$ ". The forecasting performance of each model is assessed based on the Mean Squared Percentage Error (MSPE), the Mean Absolute Percentage Error (MAPE) and the $\mathrm{R}^{2}$ of the OLS regression of the variables observed values over their forecasts yielded by the model. The meaningfulness of the differences between the forecast errors metrics is formally tested across the models using two statistical tests: the Wilcoxon signed-rank test and the impaired unilateral Student's ttest. Panel-1 reports the results of the OLS regression and the values of the forecast errors metrics for the CPT model. It also exhibits the pvalues of the statistical tests regarding the significance of the differences with the EU model and the EA model. For instance the null hypothesis under the Wilcoxon test in the case of the Squared Percentage Error (SPE) is H0: P[SPE(CPT model) $<\operatorname{SPE}(\mathrm{Competing}$ model) $]=0.5$ and the alternative hypothesis is $\mathrm{H} 1: \mathrm{P}[\mathrm{SPE}(\mathrm{CPT}$ model $)<\mathrm{SPE}($ Competing model) $]>0.5$. Similarly, panel-2 reports the EU model-related analyses results: the OLS regression statistics, the values of forecast errors metrics and the statistical tests p-values for the comparison with the EA model. Panel-3 summarises the OLS analysis and the forecast errors statistics figures for the EA model.

Models comparisons

Forecast Errors Statistics

OLS analysis

\begin{tabular}{|c|c|c|c|c|c|c|c|c|c|c|c|c|}
\hline & \multicolumn{3}{|c|}{ MSPE } & \multicolumn{3}{|c|}{ MAPE } & \multicolumn{3}{|c|}{$\tau$} & \multicolumn{3}{|c|}{$S_{\tau}$} \\
\hline & $\tau$ & $S_{\tau}$ & Combined & $\tau$ & $S_{\tau}$ & Combined & $\underset{(p \text {-value })}{\underset{\alpha}{\alpha}}$ & $\underset{(p-v a l u e)}{\boldsymbol{B}}$ & $\underline{R^{2}}$ & $\underset{(p-v a l u e)}{\underline{\alpha}}$ & $\underset{(p \text {-value })}{\boldsymbol{\beta}}$ & $\underline{R^{2}}$ \\
\hline Panel 1: CPT model & 0.267 & 1.152 & 1.419 & 0.436 & 0.626 & 1.062 & $\begin{array}{c}\mathbf{- 3 . 6 8 1} \\
(0.000)\end{array}$ & $\begin{array}{l}\mathbf{1 . 8 2 9} \\
(0.000)\end{array}$ & 0.187 & $\begin{array}{l}\mathbf{0 . 2 4 3} \\
(0.000)\end{array}$ & $\begin{array}{l}\mathbf{1 . 2 3 1} \\
(0.000)\end{array}$ & 0.083 \\
\hline - Against EU mode & & & & & & & & & & & & \\
\hline Wilcoxon (p-value) & 0.000 & 1.000 & 0.000 & 0.000 & 1.000 & 1.000 & & & & & & \\
\hline $\begin{array}{l}\text { T-test (p-value) } \\
\text { - Against EA model }\end{array}$ & 0.000 & 0.000 & 0.000 & 0.000 & 0.000 & 0.000 & & & & & & \\
\hline Wilcoxon (p-value) & 1.000 & 0.007 & 1.000 & 0.000 & 0.007 & 0.000 & & & & & & \\
\hline T-test (p-value) & 0.000 & 0.000 & 0.000 & 0.000 & 0.000 & 0.000 & & & & & & \\
\hline Panel 2: EU model & 0.313 & 1.967 & 2.280 & 0.461 & 0.719 & 1.180 & $\begin{array}{c}\mathbf{- 2 . 8 0 8} \\
(0.000)\end{array}$ & $\begin{array}{l}\mathbf{1 . 6 9 3} \\
(0.000)\end{array}$ & 0.099 & $\begin{array}{l}\mathbf{1 . 5 7 8} \\
(0.000)\end{array}$ & $\begin{array}{l}\mathbf{0 . 5 3 6} \\
(0.000)\end{array}$ & 0.015 \\
\hline - Against EA mode & & & & & & & & & & & & \\
\hline Wilcoxon (p-value) & 0.000 & 0.210 & 0.942 & 0.000 & 0.210 & 1.000 & & & & & & \\
\hline T-test (p-value) & 0.000 & 0.000 & 0.000 & 0.000 & 0.000 & 0.000 & & & & & & \\
\hline Panel 3: EA model & 0.250 & 1.621 & 1.871 & 0.429 & 0.671 & 1.100 & $\begin{array}{l}\mathbf{- 2 . 7 8 5} \\
(0.000)\end{array}$ & $\begin{array}{l}\mathbf{1 . 5 2 9} \\
(0.000)\end{array}$ & 0.144 & $\begin{array}{l}\mathbf{1 . 4 8 7} \\
(0.000)\end{array}$ & $\begin{array}{l}\mathbf{0 . 5 6 1} \\
(0.000)\end{array}$ & 0.021 \\
\hline
\end{tabular}

Table-5 provides the empirical analysis results for alternative calibrations \#2. Recall that this analysis relies on the assumption that the employees have no chance to leave their companies. It therefore neglects the effect of the non-market factors and aims only to compare the predictive performance of the risk preferences models. The figures exhibited in panel-3 denote a perceptible decline in the predictive performance of the American model, specifically with regards to the MSPE of the exercise stock price ratio forecasts. Actually, the fact that the exit probability is nil makes the exercises happen latter and deeper in the money. By contrast, the forecast errors of the CPT model 
have not significantly moved compared to the base case calibration. Overall, the yielded forecast errors and the regression statistics in panel-1 compared to those in panel-2 show that the predictive performance of the CPT model is slightly better than that of EU model. Specifically, the MAPE of the CPT model are significantly lower than those of the EU model. The forecast MSPE are also lower, but the differences are not statistically meaningful. However, the two models yield comparable OLS regression $\mathrm{R}^{2}$.

Table-5: Models comparison under the calibrations ignoring the non-market factors

This table presents the results of the comparison of the models under their respective calibrations ignoring the non-market factors (i.e. alternatives \#2). Mean variables of interest in this analysis are the exercise stock price ratio " $S_{\tau}$ " and the lifetime of the option " $\tau$ ". The forecasting performance of each model is assessed based on the Mean Squared Percentage Error (MSPE), the Mean Absolute Percentage Error (MAPE) and the $\mathrm{R}^{2}$ of the OLS regression of the variables observed values over their forecasts yield by the model. The meaningfulness of the differences between the forecast errors metrics is formally tested across the models using two statistical tests: the Wilcoxon signed-rank test and the impaired unilateral Student's t-test. Panel-1 reports the results of the OLS regression and the values of the forecast errors metrics for the CPT model. It also exhibits the p-values of the statistical tests regarding the significance of the differences with the EU model and the standard American model. For instance the null hypothesis under the Wilcoxon test in the case of the Squared Percentage Error (SPE) is H0: P[SPE(CPT model) $<\mathrm{SPE}(\mathrm{Competing}$ model) $]=0.5$ and the alternative hypothesis is H1: $\mathrm{P}[\mathrm{SPE}(\mathrm{CPT}$ model $)<\mathrm{SPE}(\mathrm{Competing}$ model $)]>0.5$. Similarly, panel-2 reports the EU model-related analyses results: the OLS regression statistics, the values of the forecast errors metrics and the statistical tests p-values for the comparison with the American model. Panel-3 summarises the OLS analysis and the forecast errors statistics figures for the American model.

Models comparisons

Forecast Errors Statistics

OLS analysis

\begin{tabular}{|c|c|c|c|c|c|c|c|c|c|c|c|c|}
\hline & \multicolumn{3}{|c|}{ MSPE } & \multicolumn{3}{|c|}{ MAPE } & \multicolumn{3}{|c|}{$\tau$} & \multicolumn{3}{|c|}{$S_{\tau}$} \\
\hline & $\tau$ & $S_{\tau}$ & Combined & $\tau$ & $S_{\tau}$ & $\underline{\text { Combined }}$ & $\begin{array}{c}\underline{\alpha} \\
(p \text {-value })\end{array}$ & $\underset{(p-v a l u e)}{\underline{\beta}}$ & $\underline{R^{2}}$ & $\begin{array}{c}\underline{\boldsymbol{\alpha}} \\
(p- \\
\text { value })\end{array}$ & $\begin{array}{c}\boldsymbol{\beta} \\
(p- \\
\text { value })\end{array}$ & $\underline{R^{2}}$ \\
\hline Panel 1: CPT model & 0.206 & 1.337 & 1.543 & 0.379 & 0.586 & 0.965 & $\begin{array}{r}\mathbf{- 1 . 0 4 6} \\
(0.000)\end{array}$ & $\begin{array}{l}\mathbf{1 . 0 9 9} \\
(0.000)\end{array}$ & 0.271 & $\begin{array}{r}\mathbf{1 . 4 2 0} \\
(0.000)\end{array}$ & $\begin{array}{l}\mathbf{0 . 5 0 9} \\
(0.000)\end{array}$ & 0.024 \\
\hline - Against EU model & & & & & & & & & & & & \\
\hline Wilcoxon (p-value) & 0.000 & 1.000 & 0.000 & 0.000 & 1.000 & 0.000 & & & & & & \\
\hline $\begin{array}{l}\text { T-test ( } p \text {-value) } \\
\text { - Against EA model }\end{array}$ & 0.761 & 0.267 & 0.415 & 0.000 & 0.019 & 0.002 & & & & & & \\
\hline Wilcoxon ( $p$-value) & 0.000 & 0.000 & 0.000 & 0.000 & 0.000 & 0.000 & & & & & & \\
\hline T-test ( $p$-value) & 0.000 & 0.000 & 0.000 & 0.000 & 0.000 & 0.000 & & & & & & \\
\hline Panel 2: EU model & 0.202 & 1.429 & 1.631 & 0.386 & 0.602 & 0.988 & $\begin{array}{l}\mathbf{- 1 . 3 1 6} \\
(0.000)\end{array}$ & $\begin{array}{l}\mathbf{1 . 1 3 1} \\
(0.000)\end{array}$ & 0.209 & $\begin{array}{l}\mathbf{0 . 3 9 1} \\
(0.000)\end{array}$ & $\begin{array}{l}\mathbf{1 . 0 9 9} \\
(0.000)\end{array}$ & 0.049 \\
\hline - Against EA model & & & & & & & & & & & & \\
\hline Wilcoxon ( $p$-value) & 0.000 & 0.000 & 0.000 & 0.000 & 0.000 & 0.000 & & & & & & \\
\hline T-test ( $p$-value) & 0.000 & 0.000 & 0.000 & 0.000 & 0.000 & 0.000 & & & & & & \\
\hline $\begin{array}{l}\text { Panel 3: American } \\
\text { model }\end{array}$ & 0.302 & 33.681 & 33.983 & 0.483 & 0.805 & 1.288 & $\begin{array}{l}\mathbf{1 . 5 2 5} \\
(0.000)\end{array}$ & $\begin{array}{l}\mathbf{0 . 3 3 9} \\
(0.000)\end{array}$ & 0.052 & $\begin{array}{l}\mathbf{1 . 7 0 0} \\
(0.000)\end{array}$ & $\begin{array}{l}\mathbf{0 . 2 8 0} \\
(0.000)\end{array}$ & 0.051 \\
\hline
\end{tabular}

In summary, relying on the base case calibrations, the CPT model shows a significant improvement over the EU model and EA model in terms of both the size of the forecast errors and the explanatory power of the regression. Even when relaxing the assumptions regarding the exogenous non-market factors, the CPT model yields slightly better forecasts compared to those of the EU model. Therefore, the CPT framework turns out to be the best candidate in explaining exercise patterns in the sample. 


\subsection{Additional robustness analyses: reference point specification}

As previously underscored, given that the literature is still largely silent on the way a stock options holder would set and adapt his reference point, the specification of the reference point is the main element that may affect the robustness of the empirical results. Therefore, I performed a robustness analysis based on alternative specifications of the reference point. The common assumption underlying these alternative specifications states that the employee relies on the BS value of the option to set the reference point. Actually, the intuition behind this assumption is supported by common practices in terms of stock option-based compensation. Most of stock options designers use the BS model in order to estimate the value of these constituents of the employees total compensation packages. This value is usually announced to the employee at the inception of the options. Moreover, the BS model is recommended in the FASB and the IASC guidelines for determining the fair value of stock options that needs to be disclosed in the financial statements. These statements, comprising the BS value of the stock options, are provided to shareholders as well as stakeholders including employees.

The first alternative specification (AS \#1) is the current BS value of the option, denoted by “ $\pi($.$) ", based on the stock price yielded by the employee own expectation regarding the annual return$ " $\rho$ " over the option lifetime. The only difference between this specification and the original one is that the former uses the BS value of the option rather than its intrinsic value as used in the latter:

$$
\theta_{i}=\pi\left(S e^{(\rho-q) i \delta t}, K, \sigma, r, q, T-i \delta t\right)
$$

The second alternative (AS \#2) assumes that the reference point is set in a static way at a proportion " $\rho$ " of the BS value at the inception of the option:

$$
\theta_{i}=\rho \pi(S, K, \sigma, r, q, T)
$$

In the last alternative (AS \#3) the reference point is specified as a fraction " $\rho$ " of the current BS value of the option based on the spot price of the stock floored by the stock price value at inception:

$$
\theta_{i, j}=\rho \pi\left[\left(S, S u^{i} d^{i-j}\right)^{+}, K, \sigma, r, q, T-i \delta t\right]
$$

The common point in all these alternative specifications is that the reference point becomes dependent on the volatility of the stock price. However, while the second alternative is a static specification of the reference point that conveys the fact that the starting point is usually privileged in a benchmark role (Spranca et al., 1991), the first and the last alternatives are dynamic specifications. Specifically, the last alternative is a stochastic specification of the reference point. Consistent with 
Arkes et al. (2006) findings that people tend to adapt their reference points asymmetrically more completely over gains than over losses, this specification assumes that the reference point is adjusted to the spot price of the stock only if the latter is above its starting level at the option grant date.

I calibrated all the model alternative specifications using the base case approach. The calibration results are reported in table B1.1 in appendix B1. The calibration error statistics indicate that all of the calibrations are significant at the $1 \%$ level. In the case of AS \#2, the reference point parameter estimate " $\hat{\rho}=100 \%$ " signals that, assuming the employees in the sample would set their reference point accordingly, they will refer to the full BS value rather than to a fraction of this value. The same conclusion could be drawn from the parameter estimate yielded by the calibration of AS \#3. In the case of AS \#1, the reference point parameter estimate resulting from the calibration supports that the employee would set his reference point at a BS value based on an average stock price level resulting in an annual performance of $25.66 \%$ per annum since the option inception. Moreover, this estimate is lower than that obtained for the original specification " $\hat{\rho}=31.46 \%$ ". This difference could be interpreted as a downside adjustment due to the time value component embedded in the BS value and that makes it higher than the intrinsic value.

In order to compare the alternative specifications in terms of the predictive performance, I performed a similar analysis to that previously used in the comparison of the models in §4.2. Broadly, the results show that the specification originally used in the model outperforms all the alternative specifications. Specifically, AS \#1 is the best performing among all the alternatives and has a predictive performance close to that of the original specification: the mean forecast errors yielded by this specification are higher than those of the original specification, although the MSPE difference is not statistically significant. Its regression $\mathrm{R}^{2}$ is almost equal to that of the original specification in the case of the exercise stock price ratio forecasts, and lower for the option lifetime forecasts. By contrast, the stochastic specification of the reference point (AS \#3) turns out to be the worst performing alternative.

In summary, this analysis shows that the reference point specification based on the intrinsic value formula yields better predictive performance than the alternative specifications based on the BS formula. It confirms then the robustness of the empirical results in this paper with respect to the reference point specification. The results of this robustness analysis are also consistent with Hodge et al. (2006) findings that employees usually use heuristics to attach values to their stock options, like determining the intrinsic value from their expectations about the future stock price.

\section{Implications for the stock options fair value assessment}


The international accounting standards (IFRS 2) and the US GAAPS (SFAS 123R) require the recognition of the stock option grants costs in the financial statements at their fair values. According to the standards guidelines, the fair value of the contract has to be determined at the grant date of the option. In the special case of the cash settled contracts, suck like the Stock Appreciation Rights (SAR), the fair value has to be reassessed at each reporting date. These standards also recommend the implementation of the widely used and commonly accepted valuation approaches. Specifically, the SFAS $123 \mathrm{R}^{16}$ states that a lattice model and a closed-form model are valuation techniques meeting its criteria for estimating fair values of employee stock options, specifically mentioning the binomial model and the adjusted BS formula as examples of each, respectively. Although the statement does not specify a preference for a particular valuation technique, in practice ${ }^{17}$ most of the firms use tweaked binomial models as well as the BS model adjusted to the expected lifetime of the options. Unfortunately, these approaches disregards employee risk preferences patterns and, therefore, still do not accurately handle actual exercise behavior.

In order to compare the option faire values ${ }^{18}$ under each of the three competing models, I assessed the fair value of the stock option contract for the representative firm in the sample (i.e. the average firm). For that, I used both the base case calibrations and the alternative calibration that neglects the effect of the non-market factors (i.e. Alternative \#2). In addition, for the purpose of comparison with some methods recommended by the accounting standards and largely indoctrinated by practitioners, I computed option fair values using two benchmark models. The first one is the adjusted BS formula (ABS). This is an extension of the BS model that uses as input the expected lifetime of the option instead of its contractual expiration date. The second benchmark is the Hull and White (2004) model (HW). This model assumes that a vested option is exercised whenever the underlying stock price hits a given hurdle (called also a suboptimal factor) from below. It also allows for the possibility of exit events, pre vesting and post vesting, due to exogenous factors causing forfeiture or early exercise of the option. The suboptimal factor in the HW model is set equal to the average exercise stock price ratio in the sample (i.e. 2.46). The exit rates, pre and post vesting, are set equal to the average cancellation rate (i.e. 6.30\%). The ABS value is based on the average lifetime of the options (i.e. 4.30). In order to gain in accuracy, I used weekly time steps for all the models.

\footnotetext{
${ }^{16}$ SFAS $123 R$ paragraph A13.

${ }^{17}$ Duff \& PHELPS (2009) IFRS 2 implementation survey shows for instance that almost 85\% of the FTSE 100 companies use the BS model and binomial approaches to value complex equity based compensation schemes including stock options.

${ }^{18}$ Note that while the approach used here does not strictly follow the accounting standards guidelines in terms of the measurement of the fair value of the option, instead of the total cost of the grant, it provides however the cost per granted option. Actually, IFRS 2 makes a distinction between market based performance features and nonmarket features. Market based performance features should be included in the grant-date fair value measurement. However, the fair value of the equity instruments should not be reduced to take into consideration non-market factors or other vesting features. By contrast, fair values from our three competing models integrate cancellations due to the non-market factors.
} 
Table-6 reports the fair value estimates from the aforementioned models. As we can see from the figures in panel-1, the base case calibration of the EA model yields very low value compared to the two other models (almost 35\% lower). By contrast, the CPT model and the EU model yielded values are close (a difference of about 4\%). On the other hand, the values from the three models are significantly lower than the values computed based on the benchmark approaches. Specifically, if we consider that the CPT model is the most accurate model in the sense that it predicts the best exercise patterns, we would admit that the benchmark models overestimate the value of the representative company's stock option contract by $10 \%$ to $20 \%$. Further, when ignoring the effect of the non-market factors, the models yield higher values. These are even higher than those resulting from the ABS approach. The values, specifically those from the CPT and the American models, are however converging with the HW model value. These results show in particular that, in spite of the fact that the predictive power of the non-market factors free specifications of the CPT and the EU models is comparable to that of the base case specifications, the yielded fair value estimates are still very sensitive to the effect of the non-market factors causing cancellation or early exercise (i.e. the existence of a non-nil exit probability).

Furthermore, I performed a sensitivity analysis of the fair value estimates from each model with respect to the dividend yield and the stock price volatility. The analysis is performed by varying the parameter of interest within its range of values in the sample and recomputing the fair value from each model. The results of this analysis are provided in appendix B2. As we can see from the figures in the panel-1 table, the differences between the CPT model values and the values from the other models are increasing with the volatility. Specifically, the option values yielded by the CPT model tend to overstate those from the EU model at higher volatility levels $(\sigma \geq 50 \%)$, and the higher the volatility the wider the \% spread between the values. In addition, graph-7 shows that the CPT model values are the most sensitive to the volatility. The reason behind this is the effect of the probability weighting that tends to increase with the skewness of the distribution of the underlying stock price. This skewness is captured by the volatility parameter " $\sigma$ ": the higher the volatility, the higher the emphasis put on the tails of the distribution, the later the exercise and the higher the fair value of the option. Moreover, graph-8 shows that the EU model is the most sensitive to the dividend yield parameter. Similar to the other models, this sensitivity of the EU model tends to decrease in the dividend yield itself. On the other hand, although all the models show negative value trends with respect to the dividend yield (see the table in panel-2), the differences across the values yielded by the models do not have the same patterns: while the \% spread tends to decrease with the dividend yield between the EU model value estimates and those from the EA model, it increases at the higher dividend yield levels $(q \geq 6 \%)$ between the CPT model and the EU model.

In summary, the first finding from this analysis is that the models display different sensitivities to volatility and dividend yield. The sensitivity of the models to these market factors depends also on the 
models specifications. Let's also stress the important finding that the fair value estimates could be very different from one model to another. These discrepancies are also noticeable across models specifications. Actually, two different specifications of a model with comparable exercise patterns predictive performance could yield quite different option fair value estimates. The main reason behind that is that the predictions from the models are based on exercise variables expectations conditioned on the terminal share price level whereas the fair value is a payoff expectation unconditional to a given share price level. Therefore, beyond the ultimate purpose of improving the so-called predictive power of the model, the specification of the model has to be as proper and as robust as possible. To this end it has to accurately consider not only the factors driving the risk preferences of the employee but also the non-market factors causing early exercise or cancellation.

Table-6: Comparing option fair value estimates from each model

This table compares the values of the representative stock option contract (i.e. the average contract from the sample) from each model: " $T=9.90 " ; ~ " \sigma=31.59 \% " ; ~ " K=S=1 " ; ~ " r=5.50 \% " ; ~ " q=2.15 \% " ; ~ " t_{v}=1.80 "$; " $\mu=12.59 \% "$. Panel-1 presents the values based on the base case calibration of the models. Panel-2 exhibits the values based on the alternative calibration of the models ignoring the non-market factors. The values are compared to those from the Hull and White (2004) model (HW) and the adjusted BS approach (ABS). The suboptimal factor in the HW model is set equal to the average stock price exercise ratio in the sample (i.e. 2.46). The values of the exit rates pre and post vesting are set to the average cancellation rate in panel1 (i.e. $6.30 \%$ ) and set to zero in panel-2. The ABS value is based on the average lifetime of the options (i.e. 4.30). Figures in parentheses indicate the differences in values as \% of the HW value (resp. the ABS value).

\section{CPT model EUT model EA model}

\section{Panel-1: Base case calibration}

\begin{tabular}{cccc} 
Fair value & 0.255 & 0.265 & 0.165 \\
HW value & 0.318 & 0.318 & 0.318 \\
& $(19.66 \%)$ & $(16.62 \%)$ & $(48.06 \%)$ \\
ABS value & 0.286 & 0.286 & 0.286 \\
& $(10.72 \%)$ & $(7.34 \%)$ & $(42.29 \%)$ \\
\hline Panel-2: Alternative calibration \#2 & & & \\
Fair value & & & \\
HW value & 0.387 & 0.354 & 0.403 \\
& 0.391 & 0.391 & 0.391 \\
ABS value & $(1.02 \%)$ & $(9.46 \%)$ & $(3.07 \%)$ \\
& 0.286 & 0.286 & 0.286 \\
& $(-35.10 \%)$ & $(-23.68 \%)$ & $(-40.95 \%)$ \\
\hline
\end{tabular}

\section{Conclusion}

This research introduces an alternative theoretical model for the valuation of employee stock options and the analysis of exercise patterns. The model predictions ascertain the ability of the CPT to better explain some prominent patterns in the employee exercise behavior than the EUT. It mainly provides rationale for using the CPT framework in order to get more accurate fair value estimates of employee stock options contracts. 
The key assumption underlying this work proceeds from the CPT and states that the representative employee choices under risk display four main features. First, instead of assessing outcomes based on their contributions to his final wealth, the employee assesses outcomes utility over gains and losses determined relative to a reference level or a benchmark. The second feature is loss aversion. It conveys the experimental evidence that people are more sensitive to losses than they are to gains. The third feature consists in the principle according to which people choices display diminishing sensitivity to incremental gains and losses. The last piece is the nonlinear probability processing. It involves the well established tendency of individuals to overweight small probabilities of large gains.

I drew on this theoretical framework to build a binomial model where the exercise decision obeys to a policy that maximizes the expected utility of a representative employee exhibiting preferences as described by the CPT. As expected, the performed numerical simulations show that the exercise is delayed with an increasing probability weighting degree. These numerical results indicate also that the option fair value (resp. option lifetime) is decreasing in loss aversion and in the reference point level. Moreover, the model specification fits significantly, on average, the empirical data on stock options exercise transactions in 12 US corporations. The model calibrations yield probability weighting coefficient estimates that are consistent with the estimates from the experimental literature. In addition, relying on the base case calibrations, I obtained empirical results suggesting that the CPT model outperforms the EU model in predicting actual exercise patterns in our sample. These findings convey the main contribution of this paper which is the strong ability of the CPT framework to explain the employee exercise behavior. The last item discussed in this paper is the assessment of stock options cost to shareholders. Numerical analyses show that, assuming that the CPT model is the most accurate valuation model in the sense that it yields the best predictions of exercise patterns, the methods recommended by the accounting standards and largely indoctrinated by practitioners would overestimate the fair value of stock options and, consequently, their cost to shareholders.

More broadly, the model and the results in this work underscore the importance of gaining a thorough understanding of the behavioral factors underlying stock options holders exercise decisions in order to get comprehensive, and more apparent, perspectives on its economic consequences. These include for instance cash impacts (resp. dilution impacts) due to the early exercise of cash settled (resp. equity settled) stock options.

Given the model specification, this research has some natural limitations that have to be outlined. The first limitation is due to the specification of the reference point. Actually, empirical and experimental literature is still silent on how people set reference points when assessing complex gambles like stock option payoffs, which stands for a handicap in applying CPT. In the absence of such guidance I tested specifications consistent with both empirical evidence on people setting reference points in a dynamic fashion and firms' widespread use of the BS value as a standard for 
financial and employees compensation disclosers. Moreover, the model does not handle the resetting and the reloading provisions that are commonly used in the stock options contracts. The model could however be enhanced in order to parsimoniously integrate factors representing these provisions as suggested in a recent literature (Brenner et al., 2000; Sircar and Xiong, 2006). Another limitation of the model is due to the assumption that the employee exercises all his options at once rather than in several transactions. This assumption contrasts with the well documented phenomenon that employees tend to exercise their options in few separate large transactions or "blocks" (Henderson, 2006; Grasselli and Henderson, 2009).

Actually, block exercise of stock options is out of the focus of this research but could be a very interesting item to be explored under the lighting of the CPT. The results in this work also outline - as did some previous eminent researches in this field (Splat, 2008; Dittmann et al., 2010; Bahaji, 2011) a number of other future promising research directions in equity-based compensation incorporating the CPT framework. For instant, exploring the ability of the CPT to explain the growing use of performance shares plans instead of stock options in employee compensation would be of a great interest for future research.

\section{Appendices A}

\section{Appendix A1: Weighted probability tree construction}

In this appendix we address the problem of the construction of a skewed probability tree using the CPT probability weighting function. Let " $p_{i, j}$ " be the weighted transition probability at node $(i, j)$ and “ $\lambda_{i, j}$ " the weighted probability to reach node $(i, j)$. The latter is computed either from compounding weighted transition probabilities related to the previous adjacent nodes or from weighting the binomial probability of reaching the node as described in (3) and (4). The weighted transition probabilities are retrieved over the entire tree starting from level 0 towards level $N-I$ based on the following algorithm:

- $\underline{F o r i=0 \text { : }}$

$$
\lambda_{0,0}=1
$$

$\omega_{1,0}=\psi_{a}(1-p)$

$$
p_{0,0}=1-\frac{\omega_{1,0}}{\lambda_{0,0}}
$$

\section{- For $i>0$ :}

$\theta_{i}=\left(S e^{(\rho-q) i \delta t}-K\right)^{+}$ 
For $0<j<i$ :

$$
\begin{aligned}
& \lambda_{i, j}=p_{i-1, j-1} \lambda_{i-1, j-1}+\left(1-p_{i-1, j}\right) \lambda_{i-1, j} \\
& \omega_{i+1, j}=\left\{\begin{array}{l}
\psi_{a}\left(\sum_{k=j}^{i+1}\left(\begin{array}{l}
i+1 \\
k
\end{array}\right) p^{k}(1-p)^{1-k}\right)-\psi_{a}\left(\sum_{k=j+1}^{i+1}\left(\begin{array}{l}
i+1 \\
k
\end{array}\right) p^{k}(1-p)^{1-k}\right) \text { if }\left(S u^{j} d^{i+1-j}-K\right)^{+} \geq \theta_{i+1} \\
\psi_{a}\left(\sum_{k=0}^{j}\left(\begin{array}{l}
i+1 \\
k
\end{array}\right) p^{k}(1-p)^{1-k}\right)-\psi_{a}\left(\sum_{k=0}^{j-1}\left(\begin{array}{l}
i+1 \\
k
\end{array}\right) p^{k}(1-p)^{1-k}\right) \text { elsewhere }
\end{array}\right. \\
& p_{i, j}=1-\frac{\omega_{i+1, j}-p_{i, j-1} \lambda_{i, j-1}}{\lambda_{i, j}} \\
& >\text { For } j=0 \text { : } \\
& \lambda_{i, 0}=\left(1-p_{i-1,0}\right) \lambda_{i-1,0} \\
& \omega_{i+1,0}=\psi_{a}\left((1-p)^{i+1}\right) \\
& p_{i, 0}=1-\frac{\omega_{i+1,0}}{\lambda_{i, 0}} \\
& >\text { For } j=i \text { : } \\
& \lambda_{i, i}=p_{i-1, i-1} \lambda_{i-1, i-1} \\
& \omega_{i+1, i+1}=\psi_{a}\left(p^{i+1}\right) \\
& p_{i, i}=\frac{\omega_{i+1, i+1}}{\lambda_{i, i}}
\end{aligned}
$$

\section{Appendix A2: CPT model algorithm}

This appendix exhibits the algorithm of the stock option CPT model. Let us use the following notations:

- $h_{i, j}$ : Intrinsic value of the option at note $(i, j)$.

- $p_{i, j}$ : Weighted transition probability at node $(i, j)$ determined following the methodology in Appendix A1.

- $p^{*}$ : Risk neutral transition probability at node $(i, j)$.

- $C e_{i, j}$ : Subjective value of the option at node $(i, j)$ determined based on the certainty equivalence principle.

- $C_{i, j}$ : Risk-neutral value of the option at node $(i, j)$. 
- $V_{i, j}^{0}$ : Continuing state exercise decision outcome at node $(i, j)$.

- $V_{i, j}^{1}$ : Exit state exercise decision outcome at node $(i, j)$.

- $p_{e}$ : Exit probability.

- $\theta_{i}$ : Reference point at the $i^{\text {th }}$ level.

In addition, let the decision function " $E_{i, j}^{m \in\{0,1\}}$ " represent the exercise policy of the employee at the continuing state $(m=0)$ and the exit state $(m=1): “ E_{i, j}^{m \in\{0,1\}}=1$ ” if the employee exercises the option and " $E_{i, j}^{m \in\{0,1\}}=0$ " otherwise. The exercise policy yielded by the CPT model implies the risk-neutral value of the option " $C_{i, j}$ ". It is defined recursively following the algorithm below:

- $\underline{\text { For }} t_{i} \geq t_{v}$ :

$$
\begin{aligned}
& E_{i, j}^{0}=1 \mathrm{I}_{\left\{h_{i, j}>C_{i, j}\right\}} \\
& E_{i, j}^{1}=1 \mathrm{I}_{\left\{\left(h_{i, j}+y\right)>e_{i, j}\right\}} \\
& V_{i, j}^{0}=C_{i, j}\left(1-E_{i, j}^{0}\right)+h_{i, j} E_{i, j}^{0} \\
& V_{i, j}^{1}=C_{i, j}\left(1-E_{i, j}^{1}\right)+h_{i, j} E_{i, j}^{1}
\end{aligned}
$$

- $\underline{\text { For }} t_{i}<t_{v}:$

$E_{i, j}^{0}=0$

$E_{i, j}^{1}=1 \mathrm{I}_{\left\{y>c_{i, j}\right\}}$

$V_{i, j}^{0}=C_{i, j}$

$V_{i, j}^{1}=C_{i, j}\left(1-E_{i, j}^{1}\right)$

Where:

$t_{i}=i \delta t$

$\theta_{i}=\left(S e^{(\rho-q) i \delta t}-K\right)^{+}$

$h_{i, j}=\left(S u^{i} d^{i-j}-K\right)^{+}$

$C_{i, j}=\left[\left(1-p_{e}\right)\left(p^{*} V_{i+1, j+1}^{0}+\left(1-p^{*}\right) V_{i+1, j}^{0}\right)+p_{e}\left(p^{*} V_{i+1, j+1}^{1}+\left(1-p^{*}\right) V_{i+1, j}^{1}\right)\right] e^{-r \delta t}$

$C e_{i, j}=v_{\theta_{i}}^{-1}\left[\left(1-p_{e}\right)\left(p_{i, j} v_{\theta_{i+1}}\left(V_{i+1, j+1}^{0}\right)+\left(1-p_{i, j}\right) v_{\theta_{i+1}}\left(V_{i+1, j}^{0}\right)\right)+p_{e}\left(p_{i, j} v_{\theta_{t+1}}\left(V_{i+1, j+1}^{1}\right)+\left(1-p_{i, j}\right) v_{\theta_{i+1}}\left(V_{i+1, j}^{1}\right)\right)\right] e^{-r \delta i t}$ 
$v_{\theta}^{-1}(x)=\left\{\begin{array}{l}\theta+x^{\frac{1}{\alpha}} ; \quad x \geq 0 \\ \theta-\left(-\frac{x}{\lambda}\right)^{\frac{1}{\alpha}} ; x<0\end{array}\right.$, with $0<\alpha \leq 1$ and $\lambda \geq 1$

\section{Appendix A3: From stock options subjective values to implied stock price diffusions}

In this appendix we address the problem of the existence of a stock price diffusion process fitting European stock options subjective values.

First, consider a diffusion process described by the following SDE:

$\frac{d S}{S}=\mu(S, t) d t+\sigma(S, t) d z$

where the drift term is a given path-independent function " $\mu(S, t)$ " of the spot price and time " $t$ ". Both $\mu(S, t)$ and $\sigma(S, t)$ are assumed to be Lipschitz functions of the spot price and time " $t$ " and satisfy then the slow growth assumption (SGA).

Note " $C_{s}(S, K, t)$ " the subjective value of a European stock option with a strike price " $K$ ", a stock spot price " $S$ " and a time to expiration " $t$ ". Let's assume that the subjective value function is convex and two-times differentiable with respect to " $K$ ". This subjective value is by definition given by:

$C_{s}(S, K, t)=\int_{K}^{\infty}(s-K) \phi_{t}(s) d s$

with " $\phi_{t}(s)$ " the density function of the stock price implied by the subjective value at time " $t$ ". Differentiating twice with respect to " $K$ " leads to the general form of this density:

$\phi_{t}(s)=\frac{\partial^{2} C_{s}(S, K, t)}{\partial K^{2}}$

It is well known that " $\phi_{t}(s)$ " satisfies the Fokker-Planck equation:

$\frac{1}{2} \frac{\partial^{2}\left(S^{2} \sigma(S, t)^{2} \phi\right)}{\partial S^{2}}-\mu(t) \frac{\partial(S \phi)}{\partial S}-\frac{\partial \phi}{\partial t}=\mu(S, t) \phi$

Substituting " $\phi$ " by its value in (A.3.3) and integrating twice with respect to " $S$ " for a fixed " $t$ " leads to the following equation:

$\frac{1}{2} \sigma(K, t)^{2} K^{2} \frac{\partial^{2} C_{s}}{\partial K^{2}}-\mu(K, t) K \frac{\partial C_{s}}{\partial K}+\int_{K}^{\infty} \frac{\partial C_{s}(S, s, t)}{\partial S} \frac{\partial \mu(S, t)}{\partial S}=\frac{\partial C_{s}}{\partial t}+a(t) K+b(t)$ 
Given that " $\lim _{K \rightarrow \infty} C_{s}(K)=0$ ", it would be consistent to assume that " $\lim _{K \rightarrow \infty} \frac{\partial C_{s}(K)}{\partial t}=0 "(*)$. Moreover, according to the SGA on " $\mu(S, t)$ " and " $\sigma(S, t)$ ", the lower limit of the left hand side of (A.3.5) as " $K$ " goes to infinity is zero $(* *)$. Therefore, from $(*)$ and $(* *)$ we conclude that the boundary terms at infinity " $a$ " and " $b$ " are nil.

We get then from (A.3.5):

$\frac{1}{2} \sigma(K, t)^{2} K^{2} \frac{\partial^{2} C_{s}}{\partial K^{2}}-\mu(K, t) K \frac{\partial C_{s}}{\partial K}+\int_{K}^{\infty} \frac{\partial C_{s}(S, s, t)}{\partial S} \frac{\partial \mu(S, t)}{\partial S}-\frac{\partial C_{s}}{\partial t}=0$

Broadly, if for a given stock price " $S$ " the drift function " $\mu(S, t)$ " is known and stock options subjective values are observable for all the strike prices and the expirations, then equation (A.3.6) can be used to recover the implied values of " $\sigma(S, t)$ " which provides the whole specification of the implied diffusion process in (A.3.1).

\section{Appendices B}

\section{Appendix B1: Robustness analysis with respect to the reference point specification}

This appendix provides the results of the robustness analysis regarding the reference point specification. This analysis consists in comparing the predictive performance of the three alternative specifications (AS) described in $\S 4.4$ to that of the specification originally used in the model. Table B1.1 summarizes the statistics of the base case calibration of each model specification. Table B1.2 figures allow to compare the model predictive performance under each reference point specification. This table presents the forecasting performance statistics specific to each model specification. These include the Mean Squared Percentage Error (MSPE), the Mean Absolute Percentage Error (MAPE) and the $\mathrm{R}^{2}$ of the OLS regression of the exercise variables observed values over their forecasts yield by the model. The meaningfulness of the differences between the forecast errors values is formally tested across the model specifications using two statistical tests: the Wilcoxon signed-rank test and the impaired unilateral Student's t-test. 
Table B1.1: Base case calibrations of the model alternative specifications re the reference point

\begin{tabular}{|c|c|c|c|c|}
\hline Calibration outputs & $\begin{array}{c}\text { Original } \\
\text { specification } \\
\end{array}$ & $\begin{array}{c}\text { Alternative } \\
\text { specification \#1 } \\
\end{array}$ & $\begin{array}{c}\text { Alternative } \\
\text { specification \#2 } \\
\end{array}$ & $\begin{array}{c}\text { Alternative } \\
\text { specification \#3 } \\
\end{array}$ \\
\hline \multicolumn{5}{|l|}{ Parameters: $\hat{P}$} \\
\hline$\hat{p}_{e}$ & 0.22 & 0.25 & 0.23 & 0.22 \\
\hline$\hat{\rho}$ & $31.46 \%$ & $25.66 \%$ & $100.00 \%$ & $100.00 \%$ \\
\hline$\hat{y}$ & 0.38 & 0.25 & 0.26 & 0.30 \\
\hline$\hat{a}$ & 0.690 & 0.65 & 1.00 & 0.60 \\
\hline$\hat{\lambda}$ & 2.25 & 2.25 & 2.25 & 2.25 \\
\hline$\hat{\alpha}$ & 0.88 & 0.880 & 0.880 & 0.880 \\
\hline Calibration error: $\varepsilon(a, \rho, q, y)$ & 0.004 & 0.001 & 0.035 & 0.018 \\
\hline$\aleph^{2}$ test $(p$-value $)$ & 1.000 & 1.000 & 0.998 & 0.999 \\
\hline$\hat{S}_{\tau}$ & 2.47 & 2.48 & 2.64 & 2.21 \\
\hline$\hat{\tau}$ & 4.42 & 4.31 & 4.69 & 4.31 \\
\hline$\hat{\eta}$ & $7.23 \%$ & $7.08 \%$ & $7.02 \%$ & $7.08 \%$ \\
\hline Option fair value & 0.255 & 0.277 & 0.278 & 0.271 \\
\hline
\end{tabular}

Table B1.2: Comparison of the reference point specifications performances

\begin{tabular}{|c|c|c|c|c|c|c|c|c|c|c|c|c|}
\hline \multirow[t]{3}{*}{ Models specifications } & \multicolumn{6}{|c|}{ Forecast Errors Statistics } & \multicolumn{6}{|c|}{ OLS analysis } \\
\hline & \multicolumn{3}{|c|}{ MSPE } & \multicolumn{3}{|c|}{ MAPE } & \multicolumn{3}{|c|}{$\tau$} & \multicolumn{3}{|c|}{$S_{\tau}$} \\
\hline & $\tau$ & $S_{\tau}$ & $\underline{\text { Combined }}$ & $\tau$ & $S_{\tau}$ & $\underline{\text { Combined }}$ & $\underset{(p \text { value })}{\underline{\alpha}}$ & $\underset{(p-v a l u e)}{\boldsymbol{B}}$ & $\underline{R^{2}}$ & $\underset{(p \text {-value })}{\underline{\alpha}}$ & $\underset{(p-v a l u e)}{\boldsymbol{B}}$ & $\underline{R^{2}}$ \\
\hline Panel 1: Original specification & 0.267 & 1.152 & 1.419 & 0.436 & 0.626 & 1.062 & $\begin{array}{c}\mathbf{- 3 . 6 8 1} \\
(0.000)\end{array}$ & $\begin{array}{l}\mathbf{1 . 8 2 9} \\
(0.000)\end{array}$ & 0.187 & $\begin{array}{l}\mathbf{0 . 2 4 3} \\
(0.000)\end{array}$ & $\begin{array}{l}\mathbf{1 . 2 3 1} \\
(0.000)\end{array}$ & 0.083 \\
\hline - Against AS \#1 & & & & & & & & & & & & \\
\hline Wilcoxon (p-value) & 1.000 & 0.000 & 1.000 & 0.000 & 0.027 & 0.145 & & & & & & \\
\hline $\begin{array}{l}\text { T-test (p-value) } \\
\text { - Against AS \#2 }\end{array}$ & 0.000 & 0.063 & 0.145 & 0.000 & 0.027 & 0.000 & & & & & & \\
\hline Wilcoxon (p-value) & 0.000 & 0.000 & 0.000 & 0.000 & 0.000 & 0.000 & & & & & & \\
\hline $\begin{array}{l}\text { T-test (p-value) } \\
\text { - Against AS \#3 }\end{array}$ & 0.000 & 0.000 & 0.000 & 0.000 & 0.000 & 0.000 & & & & & & \\
\hline Wilcoxon (p-value) & 0.000 & 1.000 & 0.000 & 0.000 & 1.000 & 0.000 & & & & & & \\
\hline T-test ( $p$-value) & 0.000 & 0.000 & 0.000 & 0.000 & 0.000 & 0.000 & & & & & & \\
\hline Panel 2: AS \#1 & 0.290 & 1.188 & 1.478 & 0.449 & 0.639 & 1.088 & -2.318 & 1.558 & 0.139 & 0.063 & 1.356 & 0.090 \\
\hline - Against AS \#2 & & & & & & & $(0.000)$ & $(0.000)$ & & $(0.136)$ & $(0.000)$ & \\
\hline Wilcoxon (p-value) & 0.000 & 0.000 & 0.000 & 0.000 & 0.000 & 0.000 & & & & & & \\
\hline $\begin{array}{l}\text { T-test (p-value) } \\
\text { - Against AS \#3 }\end{array}$ & 0.468 & 0.000 & 0.000 & 0.000 & 0.000 & 0.000 & & & & & & \\
\hline Wilcoxon (p-value) & 0.000 & 1.000 & 0.000 & 0.000 & 1.000 & 0.000 & & & & & & \\
\hline T-test ( $p$-value) & 0.000 & 0.000 & 0.000 & 0.000 & 0.000 & 0.000 & & & & & & \\
\hline Panel 3: AS \#2 & 0.290 & 1.529 & 1.819 & 0.449 & 0.690 & 1.139 & -1.857 & 1.401 & 0.104 & 0.960 & 0.846 & 0.046 \\
\hline - Against AS \#3 & & & & & & & $(0.000)$ & 0.000 & & $(0.000)$ & $(0.000)$ & \\
\hline Wilcoxon (p-value) & 1.000 & 1.000 & 0.000 & 1.000 & 1.000 & 0.000 & & & & & & \\
\hline T-test ( $p$-value) & 0.000 & 0.403 & 0.000 & 0.000 & 0.000 & 0.001 & & & & & & \\
\hline Panel 4: AS \#3 & 0.334 & 1.534 & 1.868 & 0.474 & 0.692 & 1.166 & -0.641 & 1.194 & 0.068 & 0.355 & 1.285 & 0.066 \\
\hline & & & & & & & $(0.000)$ & 0.000 & & $(0.000)$ & $(0.000)$ & \\
\hline
\end{tabular}




\section{Appendix B2: Sensitivity analysis of fair value estimates}

This appendix provides comparisons of the values of the representative stock option contract (i.e. the average contract from the sample) from each model assuming different levels of dividend yield and share price volatility and using the base case parameterizations. It also provides analyses of the fair value estimates sensitivity to dividend yield and share price volatility. Panel-1 presents the fair value estimates sensitivity against the share price volatility. Panel-2 exhibits the values based on different levels of dividend yield. Figures in parentheses indicate the differences in values expressed in $\%$. Graph 7 and graph 8 plot the sensitivities of the values yielded by each model against volatility and dividend yield respectively. The sensitivity to a given parameter is computed as the value differential for a $1 \%$ change in the parameter normalized by this parameter variation.

Panel-1: varying share price volatility. The computations are based on weekly time steps and use the following

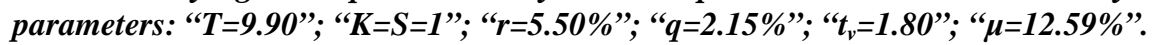

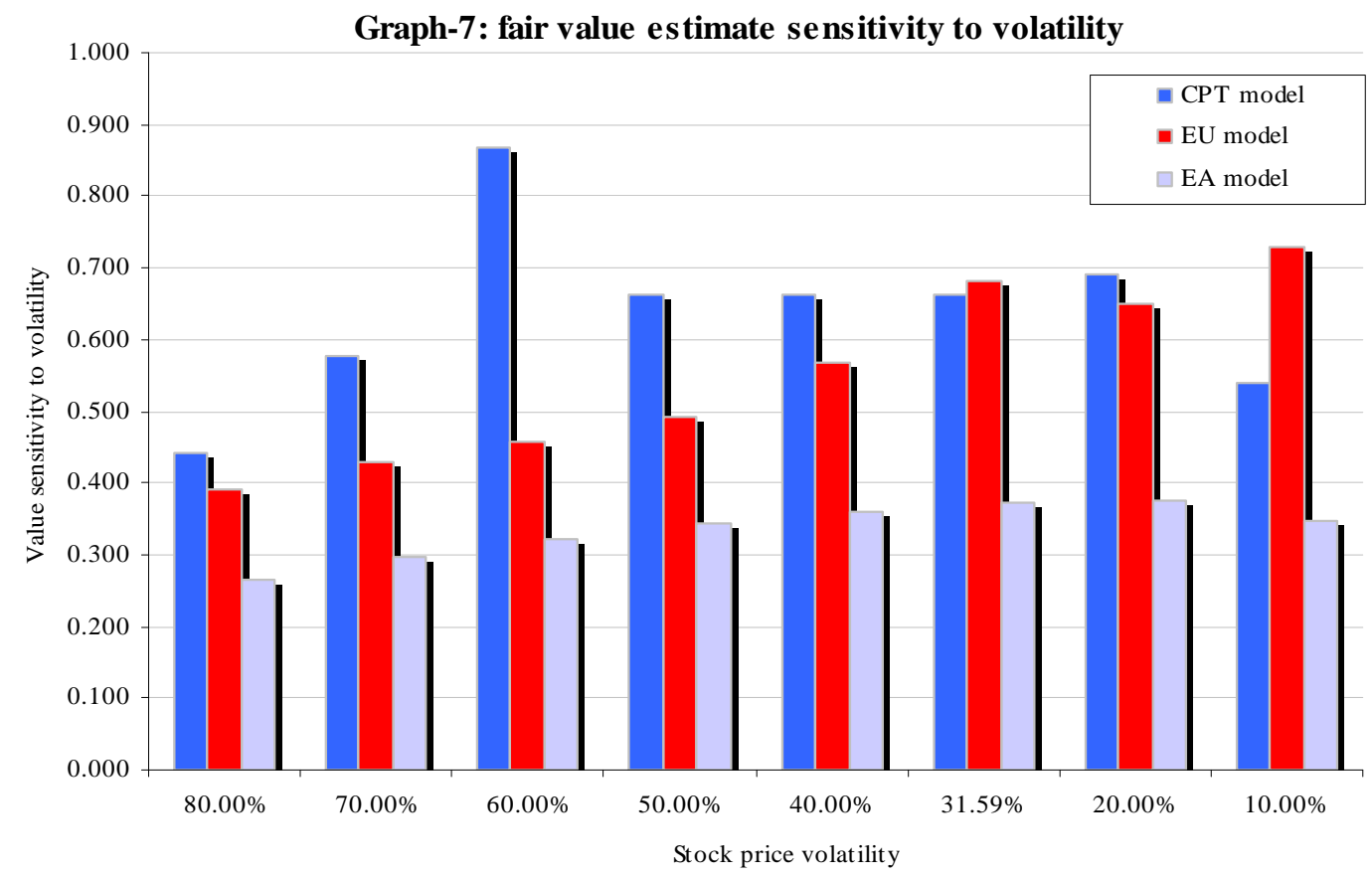




\begin{tabular}{|c|c|c|c|}
\hline $\begin{array}{c}\text { Volatility } \\
(\sigma)\end{array}$ & $\begin{array}{c}\text { CPT model } \\
(\text { Diff. EU in } \%) \\
(\text { Diff. EA in } \%)) \\
\end{array}$ & $\begin{array}{l}\text { EU model } \\
\text { (Diff. EA in } \% \text { ) }\end{array}$ & EA model \\
\hline \multirow[t]{3}{*}{$95.00 \%$} & 0.655 & 0.576 & 0.368 \\
\hline & $(12.04 \%)$ & $(36.04 \%)$ & \\
\hline & $((43.74 \%))$ & & \\
\hline \multirow[t]{3}{*}{$80.00 \%$} & 0.588 & 0.517 & 0.329 \\
\hline & $(12.10 \%)$ & $(36.48 \%)$ & \\
\hline & $((44.17 \%))$ & & \\
\hline \multirow[t]{3}{*}{$70.00 \%$} & 0.531 & 0.474 & 0.299 \\
\hline & $(10.60 \%)$ & $(36.99 \%)$ & \\
\hline & $((43.67 \%))$ & & \\
\hline \multirow[t]{3}{*}{$60.00 \%$} & 0.444 & 0.429 & 0.267 \\
\hline & $(3.43 \%)$ & $(37.73 \%)$ & \\
\hline & $((39.87 \%))$ & & \\
\hline \multirow[t]{3}{*}{$50.00 \%$} & 0.377 & 0.379 & 0.233 \\
\hline & $(-0.49 \%)$ & $(38.67 \%)$ & \\
\hline & $((38.37 \%))$ & & \\
\hline \multirow[t]{3}{*}{$40.00 \%$} & 0.311 & 0.322 & 0.196 \\
\hline & $(-3.67 \%)$ & $(39.07 \%)$ & \\
\hline & $((36.83 \%))$ & & \\
\hline \multirow[t]{3}{*}{$31.59 \%$} & 0.255 & 0.265 & 0.165 \\
\hline & $(-3.78 \%)$ & $(37.71 \%)$ & \\
\hline & $((35.36 \%))$ & & \\
\hline \multirow[t]{3}{*}{$20.00 \%$} & 0.175 & 0.190 & 0.122 \\
\hline & $(-8.31 \%)$ & $(35.93 \%)$ & \\
\hline & $((30.60 \%))$ & & \\
\hline \multirow[t]{3}{*}{$10.00 \%$} & 0.121 & 0.117 & 0.087 \\
\hline & $(3.39 \%)$ & $(25.67 \%)$ & \\
\hline & $((28.19 \%))$ & & \\
\hline
\end{tabular}

Panel-2: varying dividend yield. The computations are based on weekly time steps and use the following

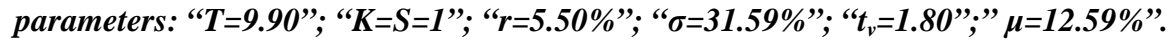

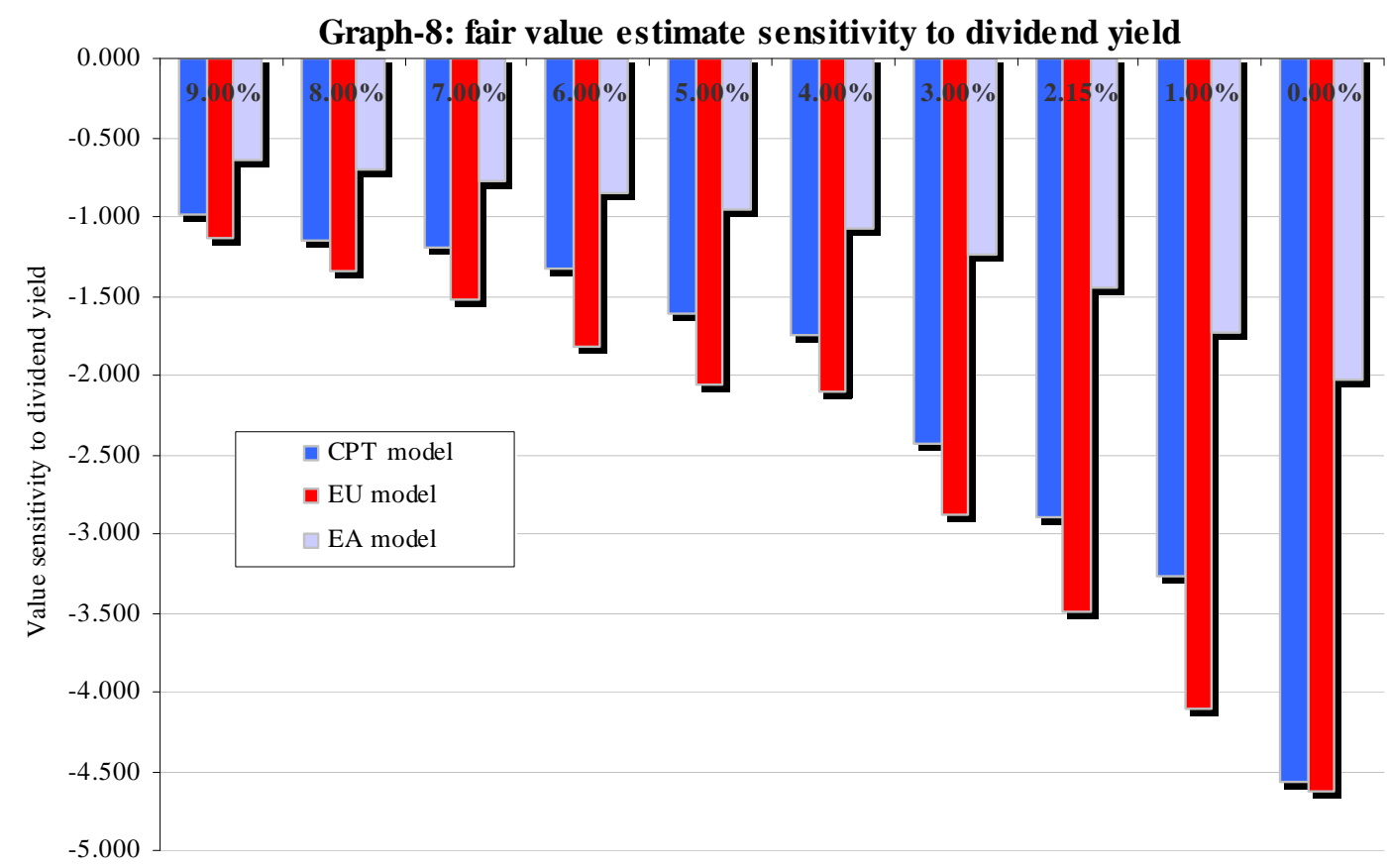




\begin{tabular}{|c|c|c|c|}
\hline $\begin{array}{c}\text { Dividend yield } \\
(q)\end{array}$ & $\begin{array}{l}\text { CPT model } \\
\text { (Diff. EU in \%) } \\
(\text { (Diff. EA in } \%)) \\
\end{array}$ & $\begin{array}{c}\text { EUT model } \\
\text { (Diff. EA in \%) }\end{array}$ & EA model \\
\hline $10.00 \%$ & $\begin{array}{c}0.126 \\
(15.83 \%) \\
((28.50 \%))\end{array}$ & $\begin{array}{c}0.106 \\
(15.05 \%)\end{array}$ & 0.090 \\
\hline $9.00 \%$ & $\begin{array}{c}0.136 \\
(13.52 \%) \\
((28.90 \%))\end{array}$ & $\begin{array}{c}0.118 \\
(17.78 \%)\end{array}$ & 0.097 \\
\hline $8.00 \%$ & $\begin{array}{c}0.148 \\
(11.12 \%) \\
((29.68 \%))\end{array}$ & $\begin{array}{l}0.131 \\
(20.88 \%)\end{array}$ & 0.104 \\
\hline $7.00 \%$ & $\begin{array}{c}0.160 \\
(8.25 \%) \\
((30.14 \%))\end{array}$ & $\begin{array}{c}0.147 \\
(23.86 \%)\end{array}$ & 0.112 \\
\hline $6.00 \%$ & $\begin{array}{c}0.173 \\
(4.75 \%) \\
((30.57 \%))\end{array}$ & $\begin{array}{c}0.165 \\
(27.11 \%)\end{array}$ & 0.120 \\
\hline $5.00 \%$ & $\begin{array}{c}0.189 \\
(1.93 \%) \\
((31.46 \%))\end{array}$ & $\begin{array}{l}0.185 \\
(30.11 \%)\end{array}$ & 0.130 \\
\hline $4.00 \%$ & $\begin{array}{c}0.206 \\
(-0.03 \%) \\
((32.02 \%))\end{array}$ & $\begin{array}{c}0.206 \\
(32.04 \%)\end{array}$ & 0.140 \\
\hline $3.00 \%$ & $\begin{array}{c}0.231 \\
(-1.98 \%) \\
((33.80 \%))\end{array}$ & $\begin{array}{c}0.235 \\
(35.08 \%)\end{array}$ & 0.153 \\
\hline $2.15 \%$ & $\begin{array}{c}0.255 \\
(-3.78 \%) \\
((35.36 \%))\end{array}$ & $\begin{array}{c}0.265 \\
(37.71 \%)\end{array}$ & 0.165 \\
\hline $1.00 \%$ & $\begin{array}{c}0.293 \\
(-6.56 \%) \\
((36.88 \%))\end{array}$ & $\begin{array}{c}0.312 \\
(40.77 \%)\end{array}$ & 0.185 \\
\hline $0.00 \%$ & $\begin{array}{c}0.339 \\
(-5.83 \%) \\
((39.40 \%))\end{array}$ & $\begin{array}{l}0.358 \\
(42.74 \%)\end{array}$ & 0.205 \\
\hline
\end{tabular}

\section{References}

[1] Arkes H. R. and Blumer C. (1985), The psychology of sunk cost, Organizational Behavior and Human Decision Processes, Vol. 35, No. 1, pp.124-140.

[2] Armstrong C., Jagolinze A. and Larcker D. (2006), Timing of employee stock option exercises and the valuation of stock option expense, Working Paper, Stanford University.

[3] Bahaji H. (2009), Le comportement d'exercice des porteurs de stock-options : une étude empirique sur le marché Américain, Working Paper, DRM Finance, Université de Paris Dauphine. 
[4] Bahaji H. (2011), Incentives from stock option grants: a behavioral approach, Review of Accounting and Finance, Vol. 10, No. 3, pp.200-227.

[5] Bettis J., Bizjak J. and Lemmon M. (2005), Exercise behavior, valuation and the incentive effects of employee stock options, Journal of Financial Economics, Vol. 76, No. 2, pp.445-470.

[6] Brenner M., Sundaram R. and Yermack D. (2000), Altering the terms of executive stock options, Journal of Financial Economics, Vol. 57, No. 1, pp.103-128.

[7] Carpenter J. (1998), The exercise and valuation of Executive stock options, Journal of Financial Economics, vol. 48, No. 2, pp.127-158.

[8] Carpenter J., Stanton R. and Wallace N. (2006), Estimation of Employee Stock Option Exercise Rates and Firm Cost: Methodology, Working Paper, New York University.

[9] Carpenter J., Stanton R. and Wallace N. (2010) Optimal Exercise of Executive Stock options and Implications for Firm Cost, Journal of Financial Economics, Vol. 98, No. 1, pp. 315-337

[10] Carr P. and Linetsky V. (2000), The valuation of executive stock options in an intensity based framework, European Financial Review, Vol. 4, No. 3, pp. 211-230.

[11] Chen H. and Rao A. (2002), Close encounters of two kinds: False alarms and dashed hopes, Marketing Science, Vol. 21, No. 2, pp.178-196.

[12] Core J.E. and Guay W. (2001), Stock option plans for non-executive employees, Journal of Financial Economics, Vol. 61, No. 2, pp.253-287.

[13] Cuny C. and Jorion P. (1995), Valuing executive stock options with an endogenous departure decision, Journal of Accounting and Economics, Vol. 20, No. 2, pp. 193-205.

[14] Cvitanic J., Wiener Z. and Zapatero F. (2004), Analytic pricing of employee stock options, Working paper, University of Southern California.

[15] Derman E. and Kani I. (1994), Riding on a smile, Risk, Vol. 7, No. 2, pp.32-39.

[16] Derman E., Kani I. and Chriss N. (1996), Implied Trinomial Trees of the volatility smile, Goldman Sachs Quantitative Strategies Research Notes, Goldman Sachs.

[17] Detemple J. and Sundaresan S. (1999), Nontraded asset valuation with portfolio constraints: A binomial approach, Review of Economic Studies, Vol. 12, No. 4, pp.835-872.

[18] Devers C., Wiseman R. and Holmes M. (2007), The effects of endowment and loss aversion in managerial stock option valuation, Academy of Management Journal, Vol. 50 No. 1, pp. 191-208.

[20] Dittmann I. and Maug E. (2007), Lower salaries and no options? On the optimal structure of Executive pay, The Journal of Finance, Vol. 62, No. 1, pp.303-343.

[21] Dittmann I., Maug E. and Spalt O.G. (2010), Sticks or Carrots? Optimal CEO Compensation when Managers are Loss Averse, Journal of Finance, Vol. 65, No. 6, pp.2015-2050.

[22] DUFF \& PHELPS (2009), A study of the implementation of IFRS 2 by FTSE 100 companies in 2006 and 2007, White paper, London.

[23] Dybvig P. and Loewenstein M. (2003), Employee reload options: pricing, hedging, and optimal exercise, Review of Financial Studies, Vol. 16, No. 1, pp. 145-171.

[24] FASB, Statement of Financial Accounting Standards No.123R, Share-Based Payment, December 2004. 
[25] Gneezy U. (1998), Updating the Reference Level: Experimental Evidence, Working paper, University of Haifa.

[26] Grasselli M. and Henderson V. (2009), Risk Aversion and Block Exercise of Executive Stock Options. Journal of Economic Dynamics and Control, Vol. 33, No. 1, pp.109-127.

[27] Hall B. and Murphy K. (2000), Optimal Exercise prices for executive stock options, American Economic Review, Vol. 90, No. 2, pp. 209-214.

[28] Hall B. and Murphy K. (2002), Stock options for undiversified executives, Journal of Accounting and Economics Vol. 33, No. 2, pp. 3-42.

[29] Hallock K. and Olson G. (2006), The value of stock options to non-executive employees, Working Paper, No. 11950, National Bureau of Economic Research, Cambridge.

[30] Heath C., Huddart S. and Lang M. (1999), Psychological factors and stock option exercise, Quarterly Journal of Economics, Vol. 114, No. 2, pp. 601-628.

[31] Heisler J. (1994), Loss aversion in a futures market: an empirical test, Review of Futures Markets, Vol. 13 No. 3, pp. 793-822.

[32] Henderson V. (2005), The impact of the market portfolio on the valuation, incentives and optimality of executive stock options, Quantitative Finance, Vol. 5, No. 1, pp. 35-47.

[33] Henderson V. (2006), Executive exercise explained: Patterns for stock options, Working paper, Princeton University.

[34] Hemmer S., Matsunaga S. and Shevlin T. (1996), The influence of risk diversification on the early exercise of employee stock options by executive officers, Journal of Accounting and Economics, Vol. 21, No. 1, pp.45-68.

[35] Hemmer T., Matsunaga S. and Shevlin T. (1998), Optimal exercise and the cost of granting employee stock options with a reload provision, Journal of Accounting Research, Vol. 36, No. 2, pp. 231-255.

[36] Hodge F. Rajgopal S. and Shevlin T. (2006), How do managers value stock options and restricted stock? Working paper, University of Washington.

[37] Huddart S. (1994), Employee stock options, Journal of Accounting and Economics, Vol. 18, No. 2, pp.207-231.

[38] Huddart S. and Lang M. (1996), Employee stock option exercises: an empirical analysis, Journal of Accounting and Economics, Vol. 21 No. 1, pp. 5-43.

[39] Hull J. and White A. (2004), How to value employee stock options, Financial Analysts Journal, Vol. 60, No. 1, pp.114-119.

[40] IASB, IFRS 2: Share-based payments, April 2004.

[41] Ibbotson Associates (2006), Stocks, Bonds, Bills, and Inflation, Valuation Edition, 2006 Yearbook.

[42] Ingersoll J. (2008), Non-Monotonicity of the Tversky-Kahneman Probability-Weighting Function: A Cautionary note, European Financial Management, Vol. 14, No. 3, pp.385-390.

[43] Jennergren L. and Naslund B. (1993), A comment on "Valuation of executive stock options and the FASB proposal", The Accounting Review, Vol. 68, No. 1, pp.179-183. 
[44] Jenter D. (2001), Understanding high-powered incentives, Working Paper, Harvard Business School and Economics Department.

[45] Kahneman D. and Tversky A. (1979), Prospect Theory: An analysis of decision under risk, Econometrica, Vol. 47 No. 2, pp. 263-292.

[46] Koszegi B. and Rabin M. (2006), A model of reference-dependent preferences, The Quarterly Journal of Economics, Vol. 121, No. 4, pp.1133-1166.

[47] Lambert R., Larcker D. and Verrecchia R. (1991), Portfolio considerations in valuing Executive Compensation, Journal of Accounting Research, Vol. 29, No. 1, pp. 129-149.

[48] Lambert R. and Larcker D. (2001), How do employees value (often incorrectly) their stock options? available at: knowledge@wharton.

[49] Marcus A. and Kulatilaka N. (1994), Valuing Employee Stock Options, Financial Analysts Journal, vol. 50, No. 5, pp.46-56.

[50] Misra L. and Shi Y. (2005), Option exercise by CEOs: overconfidence VS market timing, Working Paper, Texas University.

[51] Odean T. (1998a), Are Investors Reluctant to Realize their Losses? Journal of Finance, Vol. 53 No. 5, pp. 1775-1798.

[52] Polkovnichenko V. and Zhao F. (2009), Probability weighting functions implied by options prices, Working Paper, University of Texas, Dallas.

[53] Rubinstein M. (1994), Implied Binomial Trees, Journal of Finance, Vol. 69, No. 3, pp.771-818.

[54] Rubinstein M. (1995), On the accounting valuation of employee stock options, The Journal of Derivatives, Vol. 3, No. 1, pp.8-24.

[55] Saly P.J., Jagannathan R. and Huddart S. (1999), Valuing the reload features of executive stock options, Accounting Horizons, Vol. 13, No. 3, pp.219-240.

[56] Shefrin H. and Statman M. (1985), The disposition to sell winners too early and ride losers too long: theory and evidence, Journal of Finance, Vol. 40 No. 3, pp. 777-790.

[57] Sircar R. and Xiong W.(2006), A General Framework for Evaluating Executive Stock Options, Working paper, Princeton University.

[58] Spalt O. (2008), Probability Weighting and Employee Stock Options, Working paper, Tilburg University.

[59] Spranca M., Minsk E. and Baron J. (1991). Omission and commission in judgment and choice. Journal of Experimental Social Psychology, Vol. 27, No. 1, pp.76-105.

[60] Yogo M. (2008), Asset prices under rising aspirations and reference-dependent preferences, Journal of Business and Economic Statistics, Vol. 26, pp.131-143. 